\title{
1 SLCs contribute to endocrine resistance in breast \\ 2 cancer: role of SLC7A5 (LAT1)
}

3 Authors: Catherine M. Sevigny ${ }^{1}$, Surojeet Sengupta ${ }^{1}$, Zhexun Luo ${ }^{1}$, Xiaoyi $4 \mathrm{Liu}^{1}$, Rong Hu${ }^{1}$, Zhen Zhang ${ }^{2}$, Lu Jin ${ }^{1}$, Dominic Pearce ${ }^{3}$, Diane Demas ${ }^{1}$, 5 Ayesha N. Shajahan-Haq ${ }^{1}$, and Robert Clarke ${ }^{1}$

6 Addresses: 1) Department of Oncology, Georgetown University,

7 Washington, DC 20057. 2) Department of Pathology, Johns Hopkins

8 Medical Institutions, Baltimore, MD 21231, USA Johns Hopkins University.

9 3) Applied Bioinformatics of Cancer, University of Edinburgh Cancer

10 Research UK Centre, MRC Institute of Genetics and Molecular Medicine,

11 Edinburgh, UK

12 Short Title: LAT1 in Endocrine Resistance

13 Keywords: SLC7A5 (LAT1), Endocrine Therapy Resistance, Breast

14 Cancer

15 Corresponding Author: Catherine M. Sevigny cs1507@georgetown.edu 


\section{Abstract:}

Resistance to endocrine therapies remains a major challenge for the successful management of patients with estrogen receptor-positive $(E R+)$ breast cancers. Central to the development of resistance is the adaptive reprogramming of cellular metabolism in response to treatment. Solute carriers (SLCs) play a key role in metabolic reprogramming by transporting sugars, amino acids, and other nutrients and regulating their abundance within the cell and its subcellular organelles. We found 109 SLC mRNAs to be differentially expressed between endocrine sensitive and resistant breast cancer cells. In univariate analyses, 55 of these SLCs were associated with poor outcome in ER+ breast cancer patients. Data from TMT and SILAC studies then led us to focus on SLC7A5 (LAT1). In complex with SLC3A2 (CD98), LAT1 is the primary transporter of large, neutral amino acids including leucine and tyrosine. LAT1 expression is estrogen-regulated in endocrine sensitive cells but this regulation is lost in resistant cells. Pharmacologic inhibition or genetic depletion of LAT1 each suppressed growth in two models of endocrine resistant breast cancer. Autophagy was activated with LAT1 inhibition, but cells failed to degrade p62 showing that flux was blocked. Overexpression of the LAT1 cDNA increased protein synthesis and high LAT1 expression correlated with poor disease-free survival in ER+ breast cancer patients. This study uncovers a novel LAT1 mediated

35 adaptive response that contributes to the development of endocrine resistance. Blocking LAT1 function may offer a new avenue for effective therapeutic intervention against

\section{7 endocrine resistant ER+ breast cancers.}




\section{Introduction:}

In the United States, breast cancer is the most commonly diagnosed cancer in women $^{1}$. Of the 253,000 newly diagnosed breast cancers each year, approximately $70 \%$ are estrogen receptor positive $(\mathrm{ER}+)^{2}$. Endocrine therapies, such as aromatase inhibitors (Als) and selective estrogen receptor modulators (SERMs), have extended life expectancy for patients with ER+ disease ${ }^{3}$. Unfortunately, resistance to these treatments is common ${ }^{4,5}$. Patients who do not initially respond to endocrine therapies (de novo resistance), or who initially respond but eventually recur (acquired resistance), generally require cytotoxic chemotherapies. Chemotherapy often induces serious side effects ${ }^{6}$ but is rarely curative in advanced disease. It is critical to understand how resistance to endocrine therapy develops and to design more effective treatments for patients. Ideally, this can be achieved while minimizing toxicity. metabolism in cancer cells compared with normal cells ${ }^{7,8}$. Unique aspects of cancer cell metabolism can use pro-survival mechanisms, such as autophagy, to survive under

stress or in a nutrient-poor microenvironment. Autophagy is an intracellular process of

55 Iysosomal degradation of proteins and organelles that can release amino acids, sugars, and other essential nutrients to support cell metabolism ${ }^{9,10}$ and help to meet cellular

57 energy demand ${ }^{11}$. If proliferation does not resume and autophagy remains active at a high level, autophagy can switch from being pro-survival to activating cell death.

59 Previously, we have shown that endocrine resistant cells exhibit a higher autophagy 
61 likely contributes to maintaining the balance between pro-survival autophagy and pro-

62 apoptotic responses to endocrine therapies ${ }^{13}$.

We used established models of endocrine resistant breast cancer to assess

64 changes in the patterns of protein expression of sensitive (LCC $1^{14}$; estrogen independent,

65 tamoxifen sensitive) and resistant (LCC9 ${ }^{15}$; estrogen independent, tamoxifen and

66 fulvestrant cross resistant) cells ${ }^{15}$. We also used the T47D variants T47D:A18 (estrogen

67 dependent, tamoxifen sensitive), T47D:A18-4HT 16 (estrogen independent, tamoxifen

68 resistant) and T47D:C42 ${ }^{17}$ (estrogen receptor negative, tamoxifen resistant). Together,

69 these models reflect the endocrine therapy sensitive and resistant phenotypes that exist

70 in some patient cohorts. Differential mRNA expression analysis of endocrine sensitive

71 (LCC1) and endocrine resistant (LCC9) cells implicated several solute carriers (SLCs) in

72 acquired endocrine resistance. At the mRNA level, we found altered expression of 109

73 members of the SLC gene family; 16 of these genes were confirmed to be differentially

74 expressed by unbiased proteome analyses. Two quantitative proteomic approaches were

75 used to study differential protein expression of LCC1 and LCC9 cells: 1) tandem mass

76 tag (TMT) and 2) stable isotope labeling with amino acids in cell culture (SILAC). We

77 hypothesized that changes in solute carriers (SLCs) expression and nutrient uptake may

78 supplement autophagy to support the cellular metabolism that drives an endocrine

79 resistant phenotype.

SLCs are transport proteins that can act as exchangers, cotransporters, facilitated

81 transporters, or orphan transporters for key nutrients such as amino acids or sugars ${ }^{18}$.

82 Here we show that the solute carrier family 7 (SLC7) has several members upregulated

83 in resistant compared with sensitive cells. SLC7s transport amino acids into cells and can 
84 feed intermediate metabolism ${ }^{12,19}$. Amino acids can be modified to enter the citric acid

85 cycle, such as with the conversion of leucine into acetoacetate ${ }^{20,21}$. SLC7A5 (also known

86 as LAT1) and/or its interacting partner SLC3A2 (CD98) is upregulated in a variety of

87 cancers ${ }^{22-26}$ and is critical for growth and survival. Amino acids including the essential

88 amino acid leucine and the non-essential amino acid tyrosine are transported into the cell

89 through LAT1 $1^{23,27}$. For example, upregulation of LAT1 during androgen therapy can drive

90 pancreatic cancer progression ${ }^{22}$, whereas homozygous knockout of LAT1 is embryonic

91 lethal in mice ${ }^{28}$. We chose to focus here on LAT1 because it was significantly upregulated

92 in the LCC9 compared to the LCC1 cells in both proteome analyses and in the

93 transcriptome analysis. We now establish a critical role for LAT1 overexpression in

94 enabling the growth of endocrine resistant breast cancer cells. 


\section{Materials and Methods:}

97 Cell lines: LCC $1^{29}$ cells (antiestrogen sensitive) and LCC ${ }^{15}$ cells (antiestrogen resistant) were obtained from stocks maintained by the Georgetown Tissue Culture Shared Resource. LCC1 and LCC9 cells were cultured in 5\% charcoal stripped calf serum (CCS) in phenol red free modified IMEM media (Life Technologies). The MCF7:WS8 cells and T47D cell variants were a gift from Dr. V.C. Jordan at MD Anderson. MCF7:WS8 ${ }^{30}$ cells were maintained in $5 \%$ fetal bovine serum in modified IMEM media (Life Technologies). T47D:A18 cells and T47D:A18-4HT ${ }^{16}$ cells were grown in $5 \%$ fetal bovine serum (FBS) in RPMI (Life Technologies). T47D:C42 ${ }^{17}$ cells were grown in 5\% charcoal stripped calf serum in phenol red free modified RPMI media (Life Technologies). These cells represent acquired estrogen independence and endocrine therapy resistance in estrogen receptor positive breast cancer. All cells grown in FBS media were estrogen deprived in CCS media for 72 hours before experimental use. All experiments were done in triplicate unless stated otherwise.

Stable isotope labelling by amino acids in cell culture (SILAC): MCF7:LCC1 and MCF7:LCC9 cells were double-labelled in presence of heavy (C13) or light (C12) arginine and lysine amino acids. The cells were cultured for at least five doublings before being harvested and snap frozen. Replicates were collected using the label switch approach to assess robustness. MS Bioworks, (Ann Arbor, MI, USA) carried out the SILAC experiments. Label incorporation of more than $98 \%$ was confirmed for both the cell lines.

116 The samples were washed with PBS and lysed with RIPA. Ten microgram total protein of 117 light and heavy labelled samples were combined and the combined samples were 118 processed by SDS-PAGE. For each sample, the mobility region was excised into 20 equal 
119

120

121

122

123

124

125

126

127

128

129

130

131

132

133

134

135

136

137

138

139

140

141

sized segments. Each segment was processed by in-gel digestion. Each gel digest was analyzed by nano LC-MS/MS with a Waters NanoAcquity HPLC system interfaced to a ThermoFisher Q Exactive mass spectrometer. Data were processed using MaxQuant version 1.5.3.17 (Max Planck Institute for Biochemistry) that incorporates the Andromeda search engine.

Pharmacological agents: $17 \beta$-estradiol (Cat\# E-8875) was purchased from Millipore Sigma (MA, USA). 4-hydroxytamoxifen (Cat\# 3412) and fulvestrant (Cat\# 1047) were purchased from Tocris (Bristol, United Kingdom) and used at pharmacologically relevant concentrations $^{15,31}$. JPH203 (Cat\# 406760) was purchased from MedKoo Biosciences Inc. (NC, USA).

Plasmids and transfections: SLC7A5 siRNA and plasmid DNA were obtained from OriGene. Products used were SLC7A5 (ID 8140) Trilencer-27 Human siRNA and SLC7A5 (NM_003486) Human cDNA ORF Clone. GRP78 (HSP5A) siRNA was purchased from Dharmacon (L-008198-00-0005). Transfections for siRNA used Invitrogen's Lipofectamine RNAiMAX and for plasmid DNA we used Lipofectamine LTX Plus (ThermoFisher, MA, USA). Cells were treated for 24 hours then refed with fresh growth medium for another 48 hours before collection for protein or growth assay in knockdown experiments. For overexpression experiments, cells were transfected with the appropriate cDNA construct for 4 hours in serum free media before the media was changed to $5 \%$ CCS IMEM for an additional 44 hours.

Crystal violet cell assay: To measure changes in cell growth, 10,000-15,000 cells were plated into each well of a 24 -well plate. Treatments were started after 24 hours of seeding (Day 0) and the initial plate was collected as the baseline measurement. At the time of 
142 harvest, cells were washed with 1 X PBS and rocked in $200 \mu \mathrm{L}$ crystal violet solution (2.5

$143 \mathrm{~g}$ crystal violet, $125 \mathrm{~mL}$ methanol, $375 \mathrm{~mL}$ water) for 30 minutes. Plates were rinsed in

144 deionized water and allowed to air-dry for 48 hours. Once all time points were collected,

145 citrate buffer was used to extract dye. Analysis of the intensity of staining, which directly

146 reflects cell number, was then assessed at $570 \mathrm{~nm}$ using a VMax kinetic microplate reader

147 (Molecular Devices Corp., Menlo Park, CA) ${ }^{13,32}$.

148

149

150

151

152

153

154

155

156

157

158

159

160

161

162

163

164

Western blotting: Total protein was collected in radioimmunoprecipitation buffer (RIPA) with PhosSTOP (Roche Diagnostics, Mannheim, Germany) and Complete Mini protease inhibitor cocktail tablets (EMD Chemicals Inc. San Diego, CA). Quantification was done using Pierce BCA protein assay (Thermo Fischer Scientific) and $20 \mu \mathrm{g}$ were separated by NuPAGE $4-12 \%$ Bis-Tris gel (Invitrogen). Primary antibodies used were LAT1 (Cat \#5347S, 1:1,000; Cell Signaling), CD98 (Cat\# sc-376815, 1:1,000; Santa Cruz), ER alpha (Cat\# sc-543, 1:1,000; Santa Cruz Biotechnology), and $\beta$-Actin (Cat\# 66009-1-Ig, 1:10,000; Protein Tech). Secondary antibodies used were Anti-rabbit IgG, HRP-linked Antibody \#7074 (1:2,000; Cell Signaling) and Anti-mouse IgG, HRP-linked Antibody \#7076 (1:2,000; Cell Signaling).

RNA isolation and qRT-PCR: RNA was isolated using the trizol reagent (Invitrogen, CA, USA) and Qiagen RNeasy mini kit (CA, USA) according to the manufacturer's instructions. $1 \mathrm{~mL}$ of trizol was used per well of a 6 -well plate, mixed with $200 \mathrm{uL}$ of chloroform, and incubated at room temperature for 15 minutes. The solution was spun at $15,000 \mathrm{rpm}$ for 15 minutes and the top aqueous layer removed and mixed with an equal volume of $70 \%$ ethanol before loading onto the column of the RNeasy kit and processed as described by the manufacturer. Quantification was done using a nano-drop ND-1000 
165 Spectrophotometer. cDNA was made using High Capacity cDNA Reverse Transcription 166 Kit (Thermo Fischer Scientific) to prepare cDNA from 1000 ng RNA. PowerUp SYBR 167 Green Master Mix from Life Technologies was used for qRT-PCR. Primers used were 168 IDT SLC7A5 (FW: CGA GGA GAA GGA AGA GGC G; RV: GTT GAG CAG CGT GAT 169 GTT CC), SLC3A2 (FW: GTC GCT CAG ACT GAC TTG CT; RV: GTT CTC ACC CCG 170 GTA GTT GG), and 36B4 (FW: GTG TTC AAT, GGC, AGC, AT; RV: GAC ACC CTC 171 CAG GAA GCG A). Analysis of the data followed the delta-delta CT method ${ }^{33}$.

172 Immunofluorescence staining: 10,000-50,000 cells were plated onto glass cover slips

17324 hours before treatment. Immunofluorescence experiments were performed on cells 174 after 24 hours of either vehicle or $1 \mathrm{nM} 17 \beta$-estradiol exposure. Cells were fixed with PBS 175 containing 3.2\% paraformaldehyde (Cat\# 15714, PA, USA) with 0.2\% Triton X-100 (Cat\#

176 T8532-500mL, SIGMA, MA, USA) for 5 minutes before being washed with PBS. Cells were incubated in methanol in the $-20^{\circ} \mathrm{C}$ for 20 minutes. Cells were washed again before being exposed to primary antibody in the presence of an antibody block containing $10 \%$

179 goat serum. Primary antibodies were as described in the western blotting protocol above; the concentration of LAT1 was 1:100 and was 1:50 for CD98. Secondary antibodies used were Alexa Fluor 594 anti-rabbit (Cat\# A-11012, Life Technologies) and Alexa Fluor 488, anti-mouse (Cat \# A-11001, Life Technologies).

183 Cell cycle analysis: Cells were fixed in 75\% ethanol and analyzed by FACS analysis 184 (Georgetown Flow Cytometry/Cell Sorting Shared Resource). Cell sorting of GFP-positive 185 cells was done in 5\% CCS Media by the Georgetown Flow Cytometry/Cell Sorting Shared 186 Resource then collected for protein or analyzed for cell cycle analysis. Data were acquired 
187 using flow cytometry (BD LSRFortessa; BD Biosciences) and data analysis was

188 performed using FCS express 6 software (De Novo Software, Glendale, CA)

189 Clinical correlation analyses: We studied only data from invasive ER+ breast cancers

190 that received at least one endocrine therapy (tamoxifen) from the following publicly

191 available datasets (GSE299034, GSE6532-a ${ }^{35}$, GSE6532-p³, GSE919536). Data were

192 analyzed as described by Pearce et $a \beta 7$. For each probe of interest, the dataset was

193 sorted by the normalized expression value in ascending order. Within each sorted sub-

194 dataset, a cursor was set to move up one sample per iteration through the entire dataset

195 starting from the sample with smallest expression value. At each iteration, survival

196 analysis was performed by comparing the samples on either side of the cursor. The

197 resulting statistics including hazard ratio and log rank test $p$-value provided one measure

198 of significance per possible division in a dataset. In this study, we used 4 independent

199 clinical datasets and 119 genes (probeset_ids). An additional unpublished dataset

200 (GSE46222) was also analyzed and the results are shown in Table 1.

201 Statistical Analysis: ANOVA was used to determine significance (SigmaPlot) with a

202 Dunnett's post hoc test applied when multiple comparisons were made to a common 203 control. 


\section{Results}

205 From microarray analysis of LCC1 and LCC9 mRNA we identified 109 differentially 206 regulated solute carriers (SLCs) ${ }^{38,39}$. Of those 109 solute carriers (SLCs), 55 were 207 associated with poor clinical outcome (Table 1). When mapped onto the proteomic data 208 (TMT and SILAC), three SLCs: SLC2A1, SLC3A2, and SLC7A5 (Table 2) were each upregulated at least 1.5 fold. We had previously studied SLC2A1 (GLUT1) and found that 210 glucose and glutamine uptake are regulated by $M Y C^{13}$. Here, we have focused on 211 SLC7A5 (LAT1) and its protein partner SLC3A2 (CD98) to determine their role in 212 endocrine therapy resistance.

213 LAT1 is regulated by estrogen and upregulated in endocrine therapy sensitive 214 cells:

215 We used MCF7, LCC1, LCC9, ${ }^{15}$ T47D:A18, T47D:C42, and T47D:4HT ${ }^{17}$ cells as models to study the role of LAT1 in endocrine resistance. From the three analyses, we found that

217 LAT1 was significantly upregulated in the endocrine resistant LCC9 compared with endocrine sensitive LCC1 cells. Previously, LAT1 (SLC7A5) mRNA has been reported to be induced by estrogen in MCF7 cells ${ }^{40}$. We confirmed this observation for LAT1

220 protein in MCF7 cells (Figure 1A) and found a similar induction in LCC1 and T47D:A18 221 cells (Figure 1A\&B). Endocrine resistant LCC9, T47D:4HT, and T47D:C42 cells 222 expressed significantly higher basal levels of total LAT1 protein than their respective 223 (sensitive) parental cell lines. Since these data infer estrogen regulation of LAT1 by the 224 estrogen receptor (ER; ESR1), we used ENCODE to analyze ChIA-PET data from MCF7 225 cells ${ }^{41,42}$. Using the integrative genomics viewer, we found an ER-occupied site on the 226 LAT1 gene (Figure 1C; Supplemental Figure 1 for whole gene) ${ }^{43}$. 
227 Endocrine sensitive cells doubled their LAT1 protein expression when treated with estrogen for 24 hours. The LAT1 mRNA and protein expression increased in response to estrogen over time in both MCF7 and LCC1 cells (Figure 1D-F). After 12 to 24 hours of estrogen treatment, LAT1 mRNA levels were significantly upregulated $(p<0.05)$. In contrast to the endocrine sensitive models, LCC9 and T47D:C42 cells both showed an

232 increase in basal LAT1 protein expression but no further increase of LAT1 was seen after 24 hours of estrogen treatment.

E2 regulation of LAT1 is lost in endocrine resistant LCC9 cells:

235 Since we observed an estrogen-induced increase of LAT1 protein and mRNA expression

resistant cells. Levels of LAT1 mRNA and protein did not change in response to estrogen regulation did not affect either basal expression levels or membrane subcellular colocation of the LAT1 and CD98 proteins. Protein co-localization was measured in immunofluorescence experiments where both MCF7 and LCC9 cells were treated with

242 either vehicle or estrogen (Figure 2C-D respectively).

\section{LAT1 is differentially expressed in response to endocrine therapy treatment:}

244 To determine the effect of endocrine therapies on LAT1 expression, combinations of estrogen and either tamoxifen or fulvestrant were used to determine how LAT1 was

246 regulated in response to estrogen treatment. MCF7 (Figure 3A), LCC1 (Figure 3B), and

247 LCC9 cells (Figure 3C) express both mRNA and protein for LAT1 and CD98. LAT1 248 expression was significantly increased in response to estrogen or tamoxifen in the 249 sensitive models but unchanged in resistant models. Fulvestrant decreased LAT1 
expression in MCF7 and LCC1 cells treated with E2 or tamoxifen, suggesting that ER

251 inhibition negatively affects LAT1 expression. Estrogen alone, tamoxifen alone, and

252 estrogen and tamoxifen cotreatment each significantly increased LAT1 mRNA $(p<0.05)$

253 in both sensitive models. In the MCF7 cells, addition of fulvestrant with tamoxifen did not

254 return LAT1 mRNA levels fully to baseline (upregulation $\mathrm{p}<0.05$ ). In the MCF7 models the

255 classical estrogen-regulated GREB1 mRNA was not upregulated in response to

256 tamoxifen but increased in response to estrogen (Supplemental Figure 2A-B). GREB1

257 mRNA was unchanged in the LCC9 cells in response to endocrine treatments

258 (Supplemental Figure 2C). In the T47D models, the same trend was seen between the 259 endocrine sensitive T47D:A18s and resistant T47D:C42 and T47D:4HT cells

260 (Supplemental Figure 3).

\section{LAT1 inhibition restricts cell growth and induces G1 arrest}

262 Since LAT1 had increased basal expression and lost estrogenic regulation in resistant cells, we targeted LAT1 function using JPH203, a tyrosine analog and selective inhibitor of LAT1 function ${ }^{44,45}$. We applied a time- (3 to 6 days) and dose-dependent study design (12.5 - $50 \mu \mathrm{M})$ to determine how MCF7 and LCC9 cells respond to JPH203 treatment

(Figure 4A-B). Growth was significantly inhibited by 50\% with $50 \mu \mathrm{M}$ JPH203 in both cell

267 lines in the presence or absence of estrogen ( $p>0.05)$. The effect of JPH203 treatment

268 increased when we reduced the concentration of essential amino acids in the media in a 269 dose-dependent manner (Supplemental Figure 4). We also used two individual siRNAs

270 to knock-down LAT1 expression. 72 hours after transfection, LAT1 protein expression 271 was decreased by $40-60 \%$ as confirmed by Western blot hybridization (Figure 4C-D). Cell

272 growth was significantly decreased with two individual siRNAs targeting LAT1 (Figure 4E, 
$273 \mathrm{p}<0.05)$ after 3 or 6 days compared with control. To determine how LAT1 inhibition

274 affected cell cycle distribution, we performed cell cycle analysis of MCF7 and LCC9 cells

275 treated with either $50 \mu \mathrm{M}$ JPH203 or with siLAT1. While JPH203 inhibition did not change

276 cell cycle phase distribution of the MCF7 or LCC9 cells, treatment with siLAT1 decreased

277 the proportion of cells in S phase (Figures 4F-H). Puromycin is an inhibitor of global

278 protein synthesis and can be used to assess translation by treating cells with a high dose

279 followed by a western blot ${ }^{46}$. LCC9 cells treated with siLAT1 followed by puromycin

280 treatment exhibited a decrease in global protein translation (Figure 4I). Targeting LAT1

281 either pharmacologically or genetically was effective in reducing growth of the resistant

282 cells.

283

284

285

286

287

288

289

290

291

292

293

294

295

\section{Overexpression of LAT1 increases S phase and global protein translation}

MCF7 and LCC1 cells were transfected with plasmids containing either a GFP-empty vector or GFP-LAT1 cDNA. Overexpression of LAT1 protein was confirmed in MCF7 and LCC1 cells by measuring protein expression (Figure 5A and 5B respectively). Fluorescence imaging of the GFP tag (Figure 5C) also confirmed plasmid expression. Puromycin treatment of transfected cells showed an increase in global protein translation (Figure 5D). In addition to increased global translation in the sensitive cells, we observed an increased trend for cells to be in S phase in both MCF7 and LCC1 cells (Figure 5E).

\section{Autophagy increases with LAT1 inhibition}

Increased autophagy is a feature of endocrine resistant cells $\mathbf{s}^{12,47}$ that may cooperate with increased nutrient scavenging by SLCs to support the restoration of metabolic homeostasis. Autophagic flux can be estimated by measuring the expression of two key proteins: LC3 and p62 ${ }^{48}$. Apoptosis can be evaluated by western blot hybridization of the 
296 cleavage of poly(ADP-ribosyl) polymerase (PARP) ${ }^{49}$. Expression of both the LC3 and p62

297 proteins was increased following siRNA knockdown of LAT1 (Figure 5A). LC3 expression

298 increased but p62 did not decrease. These data are consistent with an induction of

299 autophagy but incomplete autophagic flux. Neither PARP cleavage nor phosphorylation

300 of elF2a was observed, suggesting that apoptosis and the PERK pathway within the

301 unfolded protein response (UPR) are not required for this process. Knockdown of GRP78

302 in LCC9 cells (BiP; controls all three pathways within the UPR including PERK) produced

303 a non-significant increase in LAT1 protein expression, whereas LAT1 mRNA expression

304 was significantly increased (Figure 6C and D). These data imply either an increased rate

305 of GRP78 protein turnover or a delay in increasing mRNA translation; determining the

306 precise mechanism is beyond the scope of the current study.

307 Higher LAT1 expression correlates with poor clinical outcome

308 To determine the clinical relevance of LAT1 in endocrine-treated ER+ breast cancer, we established the association of LAT1 mRNA expression with clinical outcomes in four gene expression data sets (Figure 7, see Materials and Methods). We studied only invasive

$311 \mathrm{ER}+$ breast cancers that received at least one endocrine therapy. Data sets were 312 analyzed as described by Pearce et al. ${ }^{37}$ Higher LAT1 expression correlates with a poor 313 disease-free survival (From KM plots GSE2290 $p=0.007$, GSE6532-a $p=0.005$, 314 GSE6532-p $p=0.037$, GSE9195 $\mathrm{p}=0.01$ and Table 2). 


\section{Discussion:}

While tamoxifen and fulvestrant are effective endocrine therapies ${ }^{3}$, further

317 research is needed to prevent or overcome the development of resistance. Endocrine

318 therapy resistance, particularly in advanced disease, is a major clinical challenge for patients and their physicians. Matched sensitive and resistant cell lines are useful tools to study changes in cell processes as endocrine therapy resistance develops. By

321 performing mRNA, TMT, and SILAC analyses of differentially regulated genes, we

322 identified several key players associated with the development of acquired resistance

323 (Table1). SLC7A5 (LAT1) was significantly upregulated in the LCC9 compared with the

LCC1 cells in all three analysis. This observation led to our focus on LAT1 to determine

its role in the development or maintenance of endocrine therapy resistance.

LAT1 has been proposed as a biomarker for progression in breast cancers ${ }^{50}$.

327 However, the role of LAT1 in the context of endocrine therapy responsiveness is 328 unknown. Our study shows that LAT1 overexpression in endocrine resistant breast cancer cells contributes to their survival and growth. For example, we establish that LAT1 mRNA and protein expression are increased in endocrine resistant breast cancer cells compared with their genetically related but endocrine sensitive counterparts. LAT1 is

332 reported to be estrogen regulated ${ }^{40}$; we confirmed this observation using ER positive MCF7 and T47D breast cancer cells. Constitutive activation of the ER is one component of endocrine resistance that results in the dysregulation of a number of downstream genes $^{51}$. Notably, in endocrine resistant cells the basal expression of LAT1 was higher and its estrogenic regulation was lost. A drug-induced reduction of amino acid uptake in sensitive cells could lead to metabolic stress and ultimately cell death. Resistant cells 
must find a way to address this limitation. Upregulation of SLCs such as LAT1 could improve a cell's ability to scavenge nutrients from the tumor microenvironment, a function that is critical for cell survival ${ }^{52}$. LAT1 is responsible for the uptake of leucine and tyrosine for protein synthesis or as intermediates to enter the TCA cycle ${ }^{19,53,54}$. Increased LAT1 expression has been reported in several cancers including prostate cancer ${ }^{22}$, pleural mesothelioma ${ }^{24}$, multiple myeloma ${ }^{25}$ and non-small cell lung cancer ${ }^{26}$. Since homozygous knockout of LAT1 in embryonic lethal ${ }^{28}$, LAT1 is critical for growth and survival.

While LAT1 is under estrogen regulation in MCF7 and LCC1 cells, this is lost in the resistant cells. LAT1 expression was increased by tamoxifen treatment in both MCF7 and LCC1 cells; this increase was reduced by fulvestrant. These observations are likely reflective of the partial agonist activity of tamoxifen and further imply that LAT1 expression is under estrogenic regulation. MYC is also under estrogenic regulation and we have shown that MYC can regulate glucose and glutamine through the unfolded protein response in endocrine resistant cells ${ }^{13}$. LAT1 upregulation in endocrine resistance may cooperate with MYC-induced increases in glucose and glutamine metabolism to contribute to cell survival in the face of the stress induced by endocrine therapies.

Targeting solute carriers has not been widely explored in breast cancer. JPH203 was less effective than a targeted siRNA knockdown to restrict cell growth and induce G1 arrest. However, free tyrosine, leucine, and phenylalanine in media likely influenced the efficacy of JPH203; these and other free amino acids also may be accessible within the tumor microenvironment. siRNA knock-down of LAT1 also initiated autophagy and decreased global protein translation in endocrine resistant LCC9 cells. The latter could be controlled by activation of the UPR ${ }^{56}$, which can also regulate autophagy ${ }^{12,47}$. Inhibiting 
LAT1 would reduce amino acid uptake that could activate autophagy in an attempt to

362 restore metabolic homeostasis. However, LAT1 inhibition lead to an initiation of autophagy but flux did not complete and cell death occurred. Knocking down GRP78, the primary regulator of the unfolded protein response (UPR $)^{57}$, increased LAT1 expression after 72 hours. It is likely that the uptake of amino acids and the ability of UPR to regulate global protein translation are connected, perhaps by activating features of the UPR.

JPH203 showed antineoplastic activity and safety for biliary tract and colorectal cancer in the Phase I clinical trial reported by Okana et. al. ${ }^{58}$ While LAT1 inhibitors have not yet been tested in breast cancer patients, the drug appears to be well tolerated. Targeting LAT1 limits the amount of amino acids, particularly leucine and tyrosine, that can enter the TCA cycle or maintain the production of new proteins ${ }^{27,40}$. Using JPH203 in combination with endocrine therapies and/or mTOR inhibitors ${ }^{59}$ could prove beneficial.

373 For example, the combination of JPH203 and mTOR inhibitors could result in decreased 374 amino acid uptake and protein translation to restrict tumor cell growth. Further exploration 375 into the metabolic fate of the increased uptake of pre-formed amino acids could provide 376 useful insights into the metabolic adaptations required to maintain endocrine resistance.

377 Imaging of leucine or tyrosine with positron emission tomography (PET) ${ }^{60}$ could be 378 clinically informative as a potential biomarker of endocrine responsiveness in ER+ breast 379 tumors. 
bioRxiv preprint doi: https://doi.org/10.1101/555342; this version posted February 21,2019 . The copyright holder for this preprint (which was not certified by peer review) is the author/funder, who has granted bioRxiv a license to display the preprint in perpetuity. It is made available under aCC-BY-NC-ND 4.0 International license.

384 reported here, further study of LAT1 and its role in endocrine therapy resistance may lead

385 to novel therapeutic alternatives to improve overall survival for patients. 


\section{Acknowledgements}

388 This work was supported by Public Health Service Awards U54-CA149147, U01-

389 CA184902 (R Clarke) and Department of Defense Breast Program W81XWH-18-1-0722

390 (R Clarke) and Lombardi Comprehensive Cancer Center Support Grant (CCSG) NIH P30

391 CA051008. We thank Karen Creswell and Dan Xun for their help at the Flow Cytometry

392 Shared Resource at Georgetown-Lombardi Comprehensive Cancer Center. The views

393 and opinions of the author(s) do not reflect those of the US Army or the Department of

394 Defense. 


\section{References:}

1. Torre, L. A., Islami, F., Siegel, R. L. \& Ward, E. M. CEBP FOCUS : Global Cancer in Women Global Cancer in Women : Burden and Trends. 26, 444-458 (2017).

2. Siegel, R. L., Miller, K. D. \& Jemal, A. Cancer statistics, 2017. CA. Cancer J. Clin. 67, 730 (2017).

3. Burstein, H. J. et al. Adjuvant Endocrine Therapy for Women With Hormone ReceptorPositive Breast Cancer: ASCO Clinical Practice Guideline Focused Update. J. Clin. Oncol. JCO.18.01160 (2018). doi:10.1200/JCO.18.01160

4. Reinert, T. \& Barrios, C. H. Optimal management of hormone receptor positive metastatic breast cancer in 2016. Ther. Adv. Med. Oncol. 7, 304-320 (2015).

5. Ballinger, T. J., Meier, J. B. \& Jansen, V. M. Current Landscape of Targeted Therapies for Hormone-Receptor Positive, HER2 Negative Metastatic Breast Cancer. Front. Oncol. 8, 308 (2018).

6. Condorelli, R. \& Vaz-Luis, I. Managing side effects in adjuvant endocrine therapy for breast cancer. Expert Rev. Anticancer Ther. 18, 1101-1112 (2018).

7. Hanahan, D. \& Weinberg, R. A. Hallmarks of cancer: The next generation. Cell 144, 646674 (2011).

8. De Berardinis, R. J. \& Chandel, N. S. Fundamentals of cancer metabolism. Sci. Adv. 2, (2016).

9. Rabinowitz, J. \& White, E. Autophagy and Metabolism. Acc. Chem. Res. 45, 788-802 (2008).

10. White, E., Mehnert, J. M. \& Chan, C. S. Autophagy, Metabolism, and Cancer. 21, 50375046 (2015).

11. Mathew, R., White, E., Athew, R. M. \& Hite, E. W. Autophagy , Stress, and Cancer Metabolism : What Doesn' t Kill You Makes You Stronger Autophagy, Stress, and Cancer Metabolism : What Doesn 't Kill You Makes You Stronger. LXXVI, 389-396 (2012).

12. Cook, K. L. et al. Knockdown of estrogen receptor-a induces autophagy and inhibits antiestrogen-mediated unfolded protein response activation, promoting ROS-induced breast cancer cell death. FASEB J. 28, 3891-905 (2014).

13. Shajahan-Haq, A. N. et al. MYC regulates the unfolded protein response and glucose and glutamine uptake in endocrine resistant breast cancer. Mol. Cancer 13, 239 (2014).

14. Brunner, N., Fojo, A., Freter, C. E., Lippman, M. E. \& Clarke, R. Acquisition of Hormoneindependent Growth in MCF-7 Cells Is Accompanied by Increased Expression of Estrogen-regulated Genes but Without Detectable DNA Amplifications. Cancer Res. 53, 283-290 (1993).

15. Brunner, N. et al. MCF7-LCC9 : An Antiestrogen-resistant MCF-7 Variant in Which Acquired Resistance to the Steroidal Antiestrogen ICI 182,780 Confers an Early Cross Resistance to the Nonsteroidal Antiestrogen Tamoxifen. (1997). 
16. Murphy, C. S., Meisner, L. F., Wu, S. Q. \& Jordan, V. C. Short- and long-term estrogen deprivation of T47D human breast cancer cells in culture. Eur. J. Cancer Clin. Oncol. 25, 1777-1788 (1989).

17. Pink, J. J., Bilimoria, M. M., Assikis, J. \& Jordan, V. C. Irreversible loss of the oestrogen receptor in T47D breast cancer cells following prolonged oestrogen deprivation [published erratum appears in Br J Cancer 1997;75(10):1557]. Br J Cancer 74, 12271236 (1996).

18. Hediger, M. A. et al. The ABCs of solute carriers: Physiological, pathological and therapeutic implications of human membrane transport proteins. Pflugers Arch. Eur. J. Physiol. 447, 465-468 (2004).

19. Fotiadis, D., Kanai, Y. \& Palacín, M. Molecular Aspects of Medicine The SLC3 and SLC7 families of amino acid transporters. Mol. Aspects Med. 34, 139-158 (2013).

20. Lin, T.-C. et al. Autophagy: Resetting glutamine-dependent metabolism and oxygen consumption. Autophagy 8, 1477-1493 (2012).

21. Coon, M. J. \& Gurin, S. STUDIES ON THE CONVERSION OF RADIOACTIVE LEUCINE TO ACETOACETATE. J. Biol. Chem. 180, 1159-1167 (1949).

22. Xu, M. et al. Up-Regulation of LAT1 during Antiandrogen Therapy Contributes to Progression in Prostate Cancer Cells. J. Urol. 195, 1588-1597 (2016).

23. Verrey, F. et al. CATs and HATs: The SLC7 family of amino acid transporters. Pflugers Arch. Eur. J. Physiol. 447, 532-542 (2004).

24. Kaira, K. et al. L-Type amino acid transporter 1 (LAT1) expression in malignant pleural mesothelioma. Anticancer Res. 31, 4075-4082 (2011).

25. Isoda, A. et al. Expression of L-type amino acid transporter 1 (LAT1) as a prognostic and therapeutic indicator in multiple myeloma. Cancer Sci. 105, 1496-1502 (2014).

26. Kaira, K. et al. LAT1 expression is closely associated with hypoxic markers and mTOR in resected non-small cell lung cancer. Am. J. Transl. Res. 3, 468-478 (2011).

27. Shennan, D. B., Calvert, D. T., Travers, M. T., Kudo, Y. \& Boyd, C. A. R. A study of Lleucine, $\mathrm{L}$-phenylalanine and $\mathrm{L}$-alanine transport in the perfused rat mammary gland: Possible involvement of LAT1 and LAT2. Biochim. Biophys. Acta - Biomembr. 1564, 133139 (2002).

28. Poncet, N. et al. The catalytic subunit of the system L1 amino acid transporter (Slc7a5) facilitates nutrient signalling in mouse skeletal muscle. PLoS One 9, (2014).

29. Brunner, N. et al. Advances in Brief MCF7 / LCC2 : A 4-Hydroxytamoxifen Resistant Human Breast Cancer Variant That Retains Sensitivity to the Steroidal Antiestrogen ICI $182,7801.3229-3233$ (1993).

30. Sweeney, E. E., McDaniel, R. E., Maximov, P. Y., Fan, P. \& Jordan, V. C. Models and mechanisms of acquired antihormone resistance in breast cancer: significant clinical progress despite limitations. Horm. Mol. Biol. Clin. Investig. 9, 143-163 (2012).

31. Clarke, R. et al. Molecular and pharmacological aspects of antiestrogen resistance. J. Steroid Biochem. Mol. Biol. 76, 71-84 (2001).

32. Feoktistova, M., Geserick, P. \& Leverkus, M. Crystal violet assay for determining viability 
of cultured cells. Cold Spring Harb. Protoc. 2016, 343-346 (2016).

33. Sengupta, S., Biarnes, M. C., Clarke, R. \& Jordan, V. C. Inhibition of BET proteins impairs estrogen-mediated growth and transcription in breast cancers by pausing RNA polymerase advancement. Breast Cancer Res. Treat. 150, 265-278 (2015).

34. Sotiriou, C. et al. Gene Expression Pro fi ling in Breast Cancer: Understanding the Molecular Basis of Histologic Grade To Improve Prognosis. 98, (2006).

35. Loi, S. et al. Predicting prognosis using molecular profiling in estrogen receptor-positive breast cancer treated with tamoxifen. 12, 1-12 (2008).

36. Loi, S. et al. J OURNAL OF C LINICAL O NCOLOGY Definition of Clinically Distinct Molecular Subtypes in Estrogen Receptor - Positive Breast Carcinomas Through Genomic Grade. 25, (2019).

37. Pearce, D. A., Nirmal, A. J., Freeman, T. C. \& Sims, A. H. Continuous Biomarker Assessment by Exhaustive Survival Analysis. bioRxiv (2018).

38. Shajahan-Haq, A. N. et al. EGR1 regulates cellular metabolism and survival in endocrine resistant breast cancer. Oncotarget 8, 96865-96884 (2017).

39. Zhang, $\mathrm{H}$. et al. Integrated proteogenomic characterization of human high grade serous ovarian cancer. 166, 755-765 (2017).

40. Shennan, D. B., Thomson, J., Gow, I. F., Travers, M. T. \& Barber, M. C. L -Leucine transport in human breast cancer cells ( MCF-7 and MDA-MB-231): kinetics, regulation by estrogen and molecular identity of the transporter. 1664, 206-216 (2004).

41. Consortium, T. E. P. An Integrated Encyclopedia of DNA Elements in the Human Genome. 489, 57-74 (2012).

42. Davis, C. A. et al. The Encyclopedia of DNA elements ( ENCODE ): data portal update. 46, 794-801 (2017).

43. Robinson, J. T. et al. Integrative genomics viewer. Nat. Biotechnol. 29, 24 (2011).

44. Cormerais, Y. et al. Genetic disruption of the multifunctional CD98/LAT1 complex demonstrates the key role of essential amino acid transport in the control of mTORC1 and tumor growth. Cancer Res. 76, 4481-4492 (2016).

45. Yothaisong, S. et al. Inhibition of L-type amino acid transporter 1 activity as a new therapeutic target for cholangiocarcinoma treatment. Tumor Biol. 39, 101042831769454 (2017).

46. Schmidt, E. K., Clavarino, G., Ceppi, M. \& Pierre, P. SUnSET, a nonradioactive method to monitor protein synthesis. Nat. Methods 6, 275-277 (2009).

47. Cook, K. L. \& Clarke, R. Estrogen receptor-a signaling and localization regulates autophagy and unfolded protein response activation in ER+ breast cancer. Recept. Clin Investig 1, (2014).

48. Ohsumi, Y. Historical landmarks of autophagy research. Cell Res. 24, 9-23 (2014).

49. Nosseri, C., Coppola, S. \& Ghibelli, L. Possible Involvement of Poly(ADP-Ribosyl) Polymerase in Triggering Stress-Induced Apoptosis. Exp. Cell Res. 212, 367-373 (1994). 
50. Liang, Z. et al. Potential Biomarker of L-type Amino Acid Transporter 1 in Breast Cancer Progression. 93-102 (2011). doi:10.1007/s13139-010-0068-2

51. Cook, K. L., Shajahan, A. \& Clarke, R. Autophagy and endocrine resistance in breast cancer. Expert Rev Anticancer Ther 11, 1283-1294 (2011).

52. Martinez-Outschoorn, U. E., Peiris-Pagés, M., Pestell, R. G., Sotgia, F. \& Lisanti, M. P. Cancer metabolism: A therapeutic perspective. Nat. Rev. Clin. Oncol. 14, 11-31 (2017).

53. Devés, R., Angelo, S. \& Chávez, P. N-ethylmaleimide discriminates between two lysine transport systems in human erythrocytes. J. Physiol. 468, 753-66 (1993).

54. Shennan, D. B., Thomson, J., Barber, M. C. \& Travers, M. T. Functional and molecular characteristics of system $\mathrm{L}$ in human breast cancer cells. Biochim. Biophys. Acta Biomembr. 1611, 81-90 (2003).

55. Müller, V., Jensen, E. V. \& Knabbe, C. Partial antagonism between steroidal and nonsteroidal antiestrogens in human breast cancer cell lines. Cancer Res. 58, 263-267 (1998).

56. Guan, B. J. et al. Translational control during endoplasmic reticulum stress beyond phosphorylation of the translation initiation factor eif2. J. Biol. Chem. 289, 12593-12611 (2014).

57. Cook, K. L. et al. Endoplasmic Reticulum Stress Protein GRP78 Modulates Lipid Metabolism to Control Drug Sensitivity and Antitumor Immunity in Breast Cancer. Cancer Res. 76, 5657 LP-5670 (2016).

58. Okana, N. et al. First-in-human phase I study of JPH2O3 in patients with advanced solid tumors. J. Clin. Oncol. 36, 9-10 (2018).

59. Ueno, S., Kimura, T., Yamaga, T., Kawada, A. \& Ochiai, T. Metformin enhances antitumor effect of L-type amino acid. J. Pharmacol. Sci. 1, 1-8 (2016).

60. Sundaram, S. K. et al. Quantification of protein synthesis in the human brain using L-[111C]-leucine PET: incorporation of factors for large neutral amino acids in plasma and for amino acids recycled from tissue. J. Nucl. Med. 47, 1787-95 (2006).

61. Ansari, R. El et al. The amino acid transporter SLC7A5 confers a poor prognosis in the highly proliferative breast cancer subtypes and is a key therapeutic target in luminal $B$ tumours. Breast Cancer Res. 2018201 20, 21 (2018). 


\section{FIGURE LEGENDS}

549 Figure 1: Figure 1: LAT1 is estrogen regulated in endocrine therapy sensitive cell lines.

550 A) LAT1 and CD98 are upregulated in endocrine therapy resistant cells (LCC9s) 551 compared to sensitive cell lines (MCF7, LCC1s). B) This upregulation was observed in 552 T47D:C42 and T47D:4HTs compared to parental T47D:A18s. C) ESR1 binding on the 553 LAT1 gene. D) Increasing time of estrogen (1nM) increases LAT1 and CD98 mRNA in 554 both MCF7 and LCC1 cells. E) MCF7 and F) LCC1 cells show increased protein levels of 555 LAT1 with estrogen treatment.

556 Figure 2: LAT1 is not upregulated by estrogen in endocrine therapy resistant LCC9s. A) LAT1 nor CD98 are significantly changed at the mRNA level with estrogen treatment. B) Western blot analysis also showed no difference at the protein level. C) MCF7 and D) LCC9 cells look similar in immunofluorescent images as LAT1 and CD98 co-localize in both cell lines.

561

562

563

564

565

566

567

568

569

570

571

572

573

574

575

576

577

578

579

580

581

582

583

584

585

586

Figure 3: Endocrine therapies differentially change LAT1 expression in sensitive but not resistant cells. A) MCF7, B) LCC1, and C) LCC9 cell lines show differential LAT1 and CD98 protein or mRNA expression with endocrine therapy treatment for 24 hours. Endocrine therapy sensitive cells upregulate LAT1 and CD98 in response to estrogen and tamoxifen treatment.

Figure 4: LAT1 inhibition restricts MCF7 and LCC9 proliferation. A) MCF7 and B) LCC9 growth curves when treated with increasing doses of JPH203 for 3 and 6 days. C) siRNA targeting of LAT1 which is quantified in D) was more effective. E) Growth curve of siLAT1 cells showed a decrease in in cell growth consistent for 3 or 6 days. Cell cycle analysis of F) MCF7 and G) LCC9 with JPH203 did not yield significant results, however H) siRNA knockdown of LAT1 in LCC9s reduced S phase. I) Western blot of puromycinylated proteins showed a reduction in global protein translation with LAT1 knock down after 72 hrs.

Figure 5: LAT1 Overexpression leads to proliferative advantage in MCF7 and LCC1s. LAT1 plasmid was transfected into cells with a GFP tag. A) MCF7 cells and B) LCC1 cells were sorted for GFP positivity confirmed LAT1 overexpression through western blot. C) microscopy image shows LAT1 overexpression in MCF7s. D) MCF7 cells were treated with puromycin to show increased global protein translation with LAT1 overexpression. Cell cycle analysis shows a trend increase of S phase in both E) MCF7 and F) LCC1 cells.

Figure 6: Autophagy initiates but does not complete with LAT1 inhibition. A) markers for autophagy and the unfolded protein response show autophagic flux. B) knockdown of GRP78 shows an increase of LAT1 protein after 72 hours. C) The mRNA levels of LAT1 increase with GRP78 knockdown (one replicate is stronger than the other).

Figure 7: Clinical data sets confirm increased LAT1 expression correlates with poor disease-free survival. 
Table 1: List of significantly differentially regulated genes in LCC9s compared to LCC1s at mRNA analysis and compared with clinical data sets. Three clinical data sets are used: Edinburgh (GSE46222), LoiPlus2 (GSE9195), and Sotiriou (GSE299). For some SLCs multiple probeset_ids exist. For mRNA analysis, p value, FDR, and fold change (FC) exist with FC indicated with positive (red) numbers meaning upregulation and negative (green) numbers meaning downregulation in the LCC9 compared to the LCC1 cells. For the GSE data sets, the direction of high or low expression of the given SLC is indicated for poor prognosis with the $p$ value. Edinburgh and LoiPlus2 utilized the affymetrix HG-U133plus2 chip set while Sotirou used affymetrix HG-U133A chip set resulting in some genes not being included (marked yellow as invalid gene symbol). Non-significant KM data is marked in red as NS.

Table 2: List of significantly upregulated (1.5 fold or more) solute carriers in LCC9 cells compared to LCC1 cells in mRNA, TMT, and SILAC analysis. Red text indicates upregulation in all three data sets.

\section{Supplemental Data to Include:}

Supplemental Figure 1: ESR1 protein binds to an early portion of the LAT1 gene in MCF7 cells as shown by ChIA-PET.

Supplemental Figure 2: GREB1 is classically expressed in response to endocrine therapy treatment in MCF7 but not LCC9s. A) GREB1 mRNA expression increases with estrogen treatment. B) GREB1 mRNA does not change in response to endocrine therapy treatment showing classical estrogen regulation which is lost in C) LCC9 cells.

Supplemental Figure 3: Endocrine therapy treatment modulates LAT1 expression in A) endocrine therapy sensitive T47D:A18s but not endocrine therapy resistant B) T47D:C42s nor C) T47D:4HTs.

Supplemental Figure 4: Depleting essential amino acids in the media enhances growth arrest by JPH203 in both LCC9s and C42s. A) LCC9s or B) T47D:C42s were cultured in essential amino acid deplete media and treated with indicated concentrations of JPH203 resulting in increased efficacy. C) LCC9 and D) T47D:C42 cells had an increase in Sub G1 when analyzed by flow cytometry and E-F) both showed a decrease in S phase. 
bioRxiv preprint doi: https://doi.org/10.1101/555342; this version posted February 21, 2019. The copyright holder for this preprint (which was not certified by peer review) is the author/funder, who has granted bioRxiv a license to display the preprint in perpetuity. It is made available under aCC-BY-NC-ND 4.0 International license.

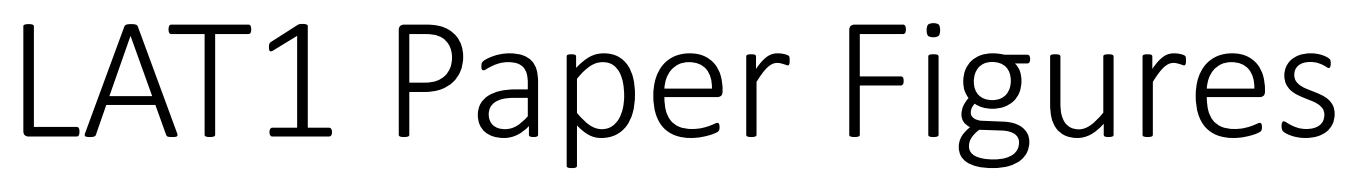


A

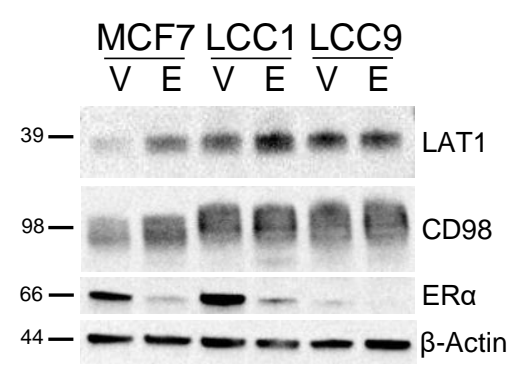

B

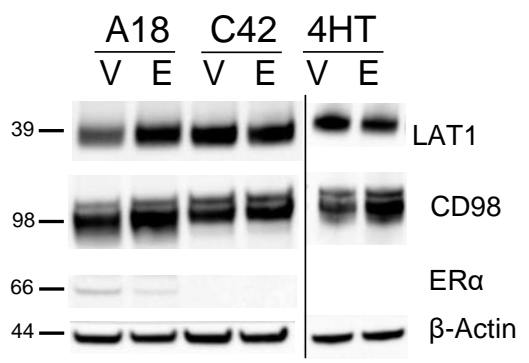

C

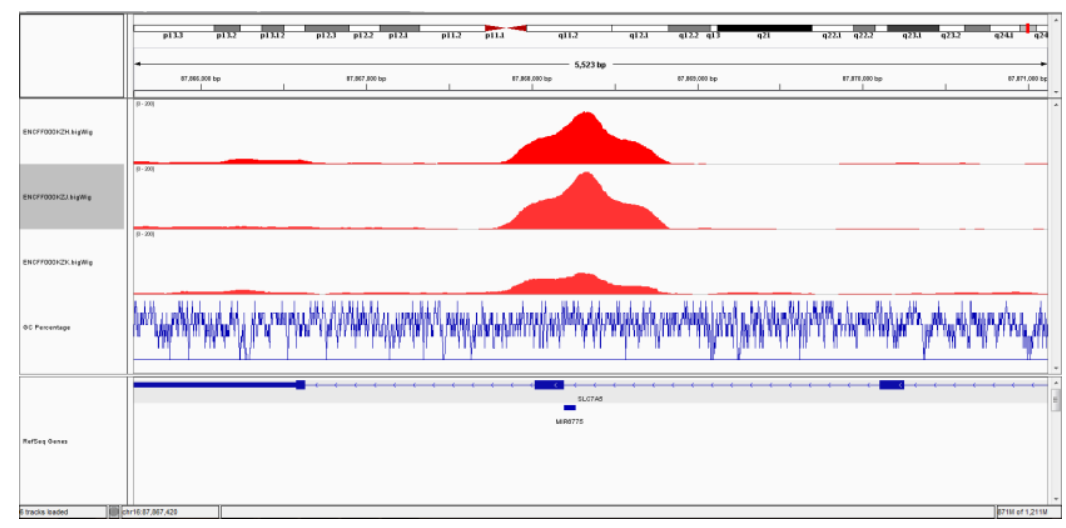

D

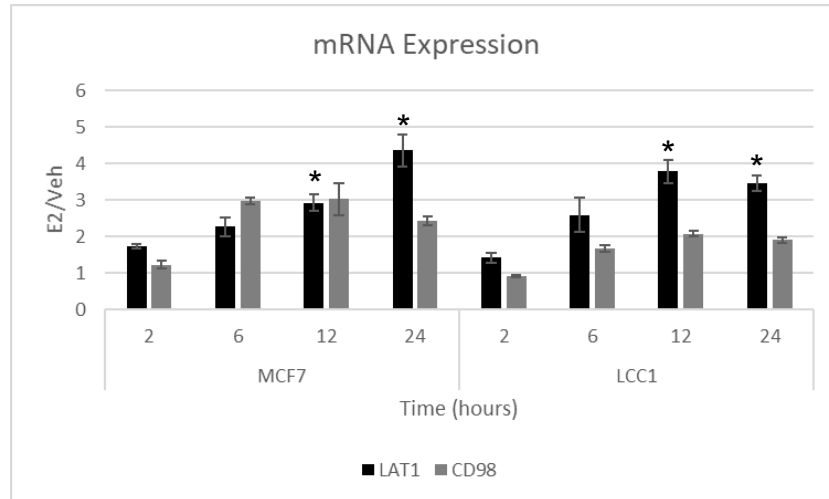

E

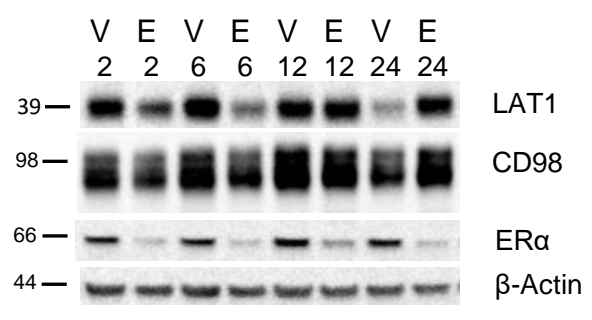

MCF7
F

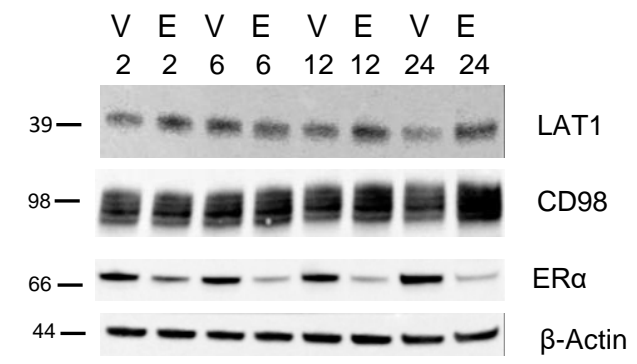

LCC1

Figure 1. 
bioRxiv preprint doi: https://doi.org/10.1101/555342; this version posted February 21, 2019. The copyright holder for this preprint (which was not certified by peer review) is the author/funder, who has granted bioRxiv a license to display the preprint in perpetuity. It is made available under aCC-BY-NC-ND 4.0 International license.

A

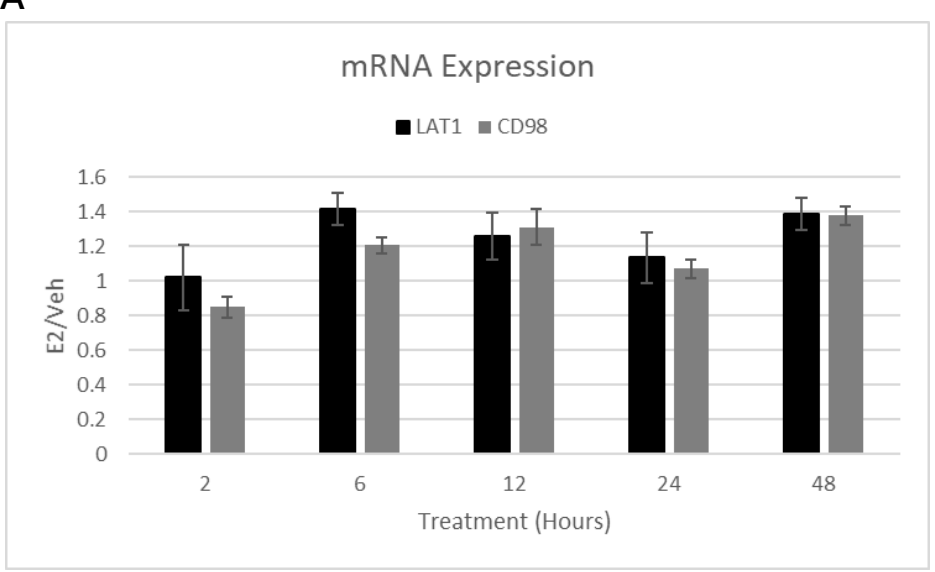

C

MCF7: DAPI, CD98, and LAT1
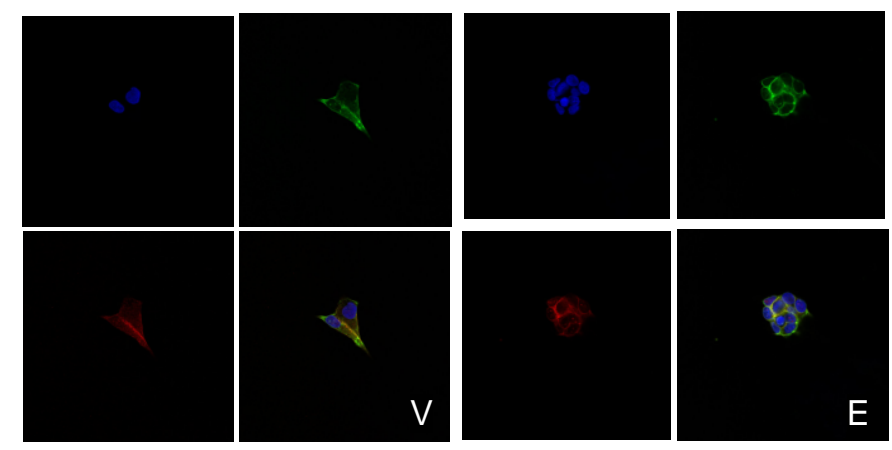

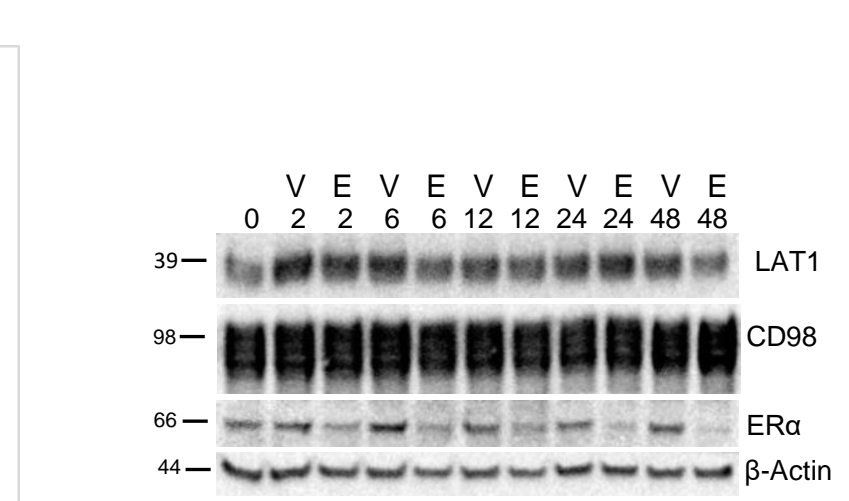

D

LCC9: DAPI, CD98, and LAT1

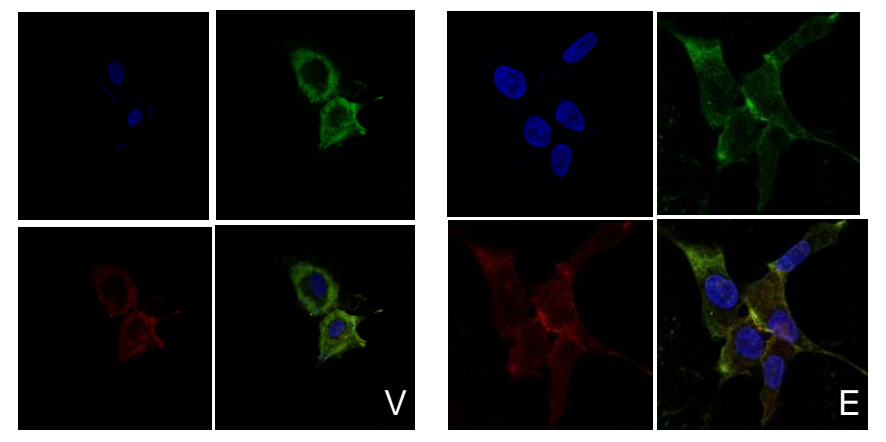

Figure 2 


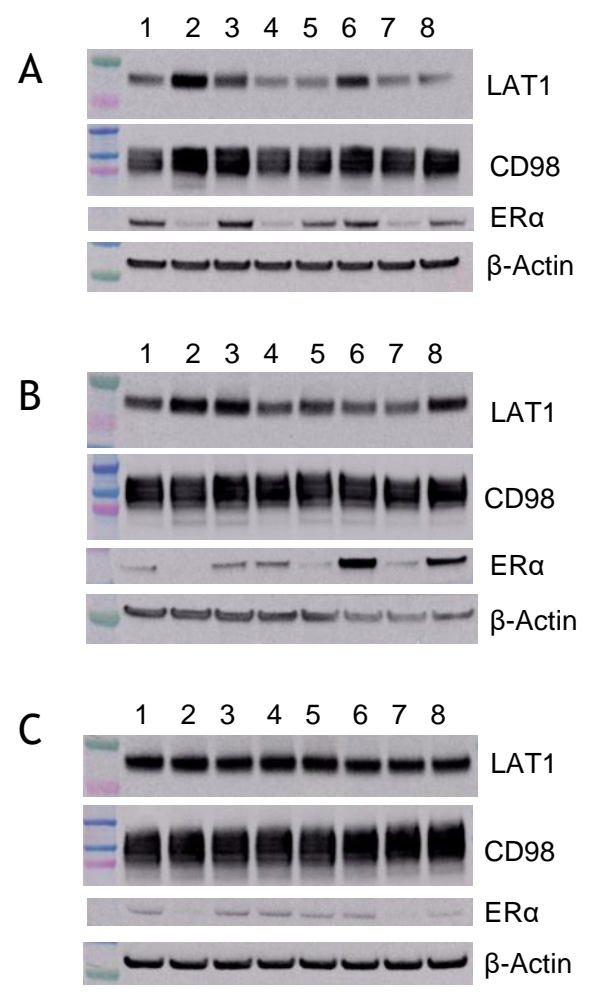

1- Ethanol,

2- 1nM 17- $\beta$-Estradiol (E2),

3- 500nM 4-OH-Tamoxifen (Tam),

4- 500nM Fulvestrant (ICl),

5- Tam + ICl, 6- E2 + Tam,

7- $\mathrm{E} 2+\mathrm{ICl}, 8-\mathrm{E} 2+\mathrm{Tam}+\mathrm{ICl}$

\section{MCF7 mRNA Expression}

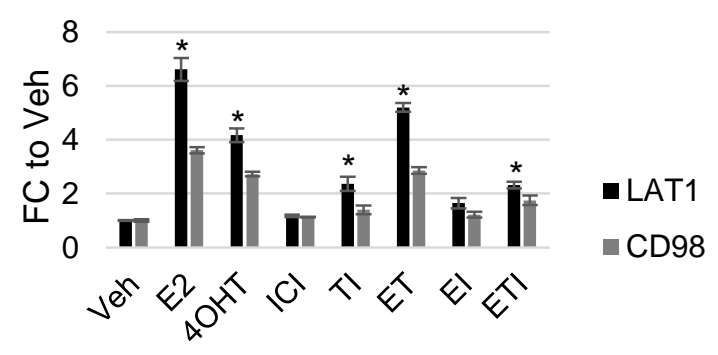

Treatments $(24 \mathrm{hrs})$

LCC1 mRNA Expression

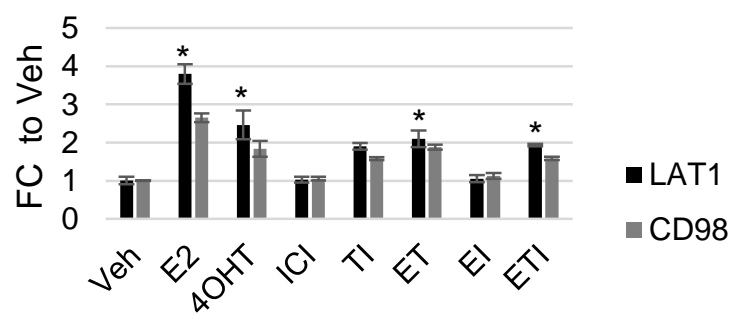

Treatments (24 hrs)

\section{LCC9 mRNA Expression}

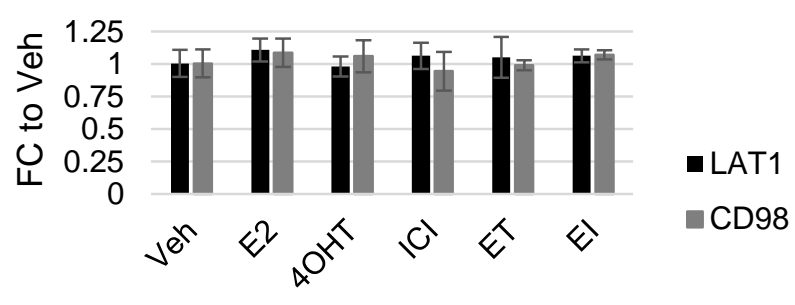

Treatments (24 hrs)

\section{Figure 3}


A

$$
\text { JPH Growth Curve in MCF7 }
$$

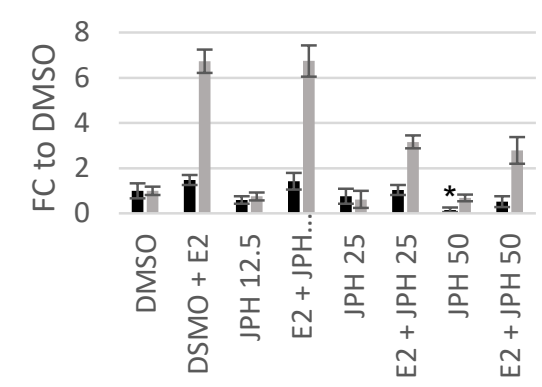

B JPH203 Growth Curve in LCC9

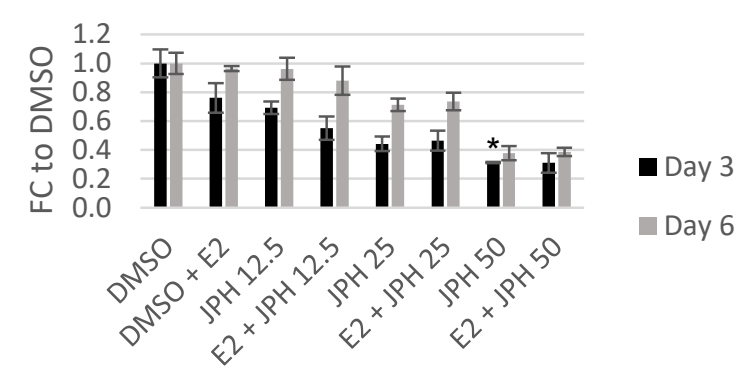

C

\begin{abstract}
Med Scr A B C
\end{abstract}

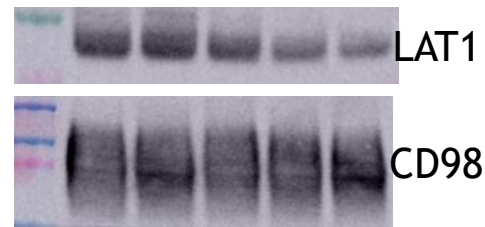

$\cup u=u_{B \text {-Actin }}$

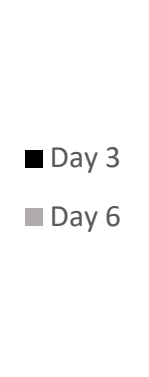

D

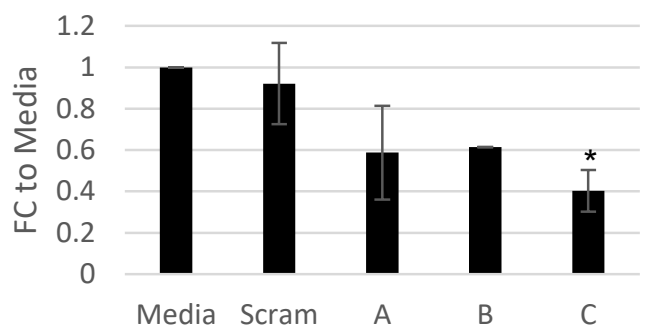

72 HR Treated
E

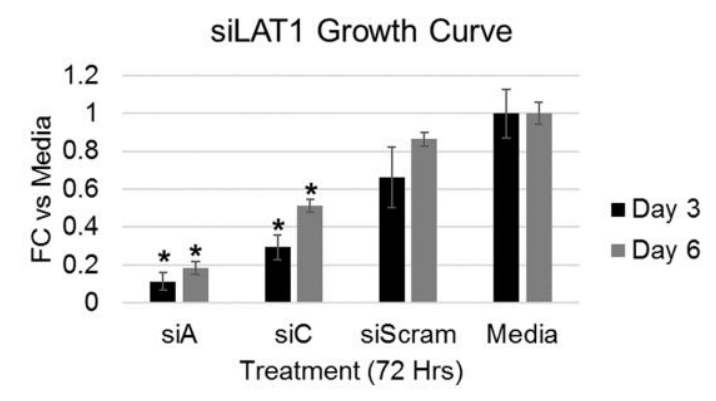

$\mathrm{H}$

G

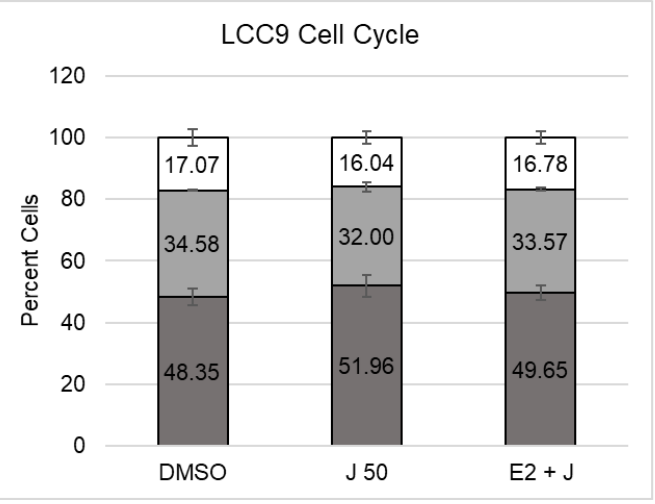

\section{Figure 4}


bioRxiv preprint doi: https://doi.org/10.1101/555342; this version posted February 21,2019 . The copyright holder for this preprint (which was not certified by peer review) is the author/funder, who has granted bioRxiv a license to display the preprint in perpetuity. It is made available under aCC-BY-NC-ND 4.0 International license.

\section{Figure 5}

A

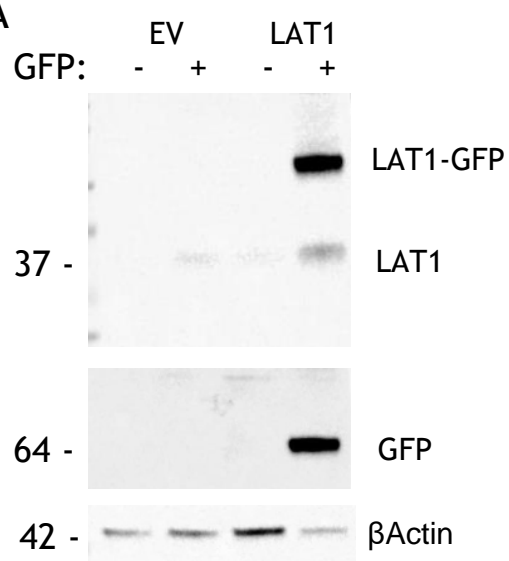

B

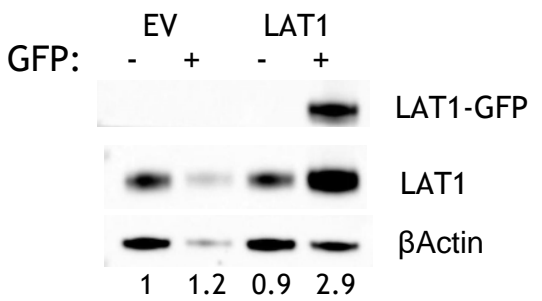

\section{LCC1}

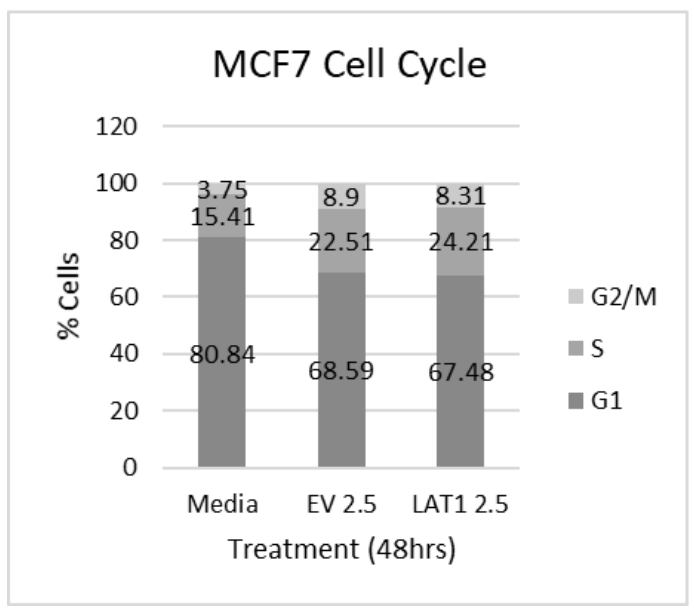

C

Brightfield

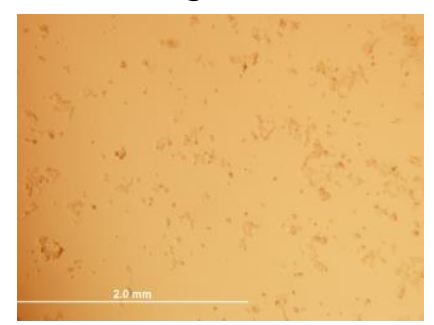

D

EV LAT1

Puro: - + - +

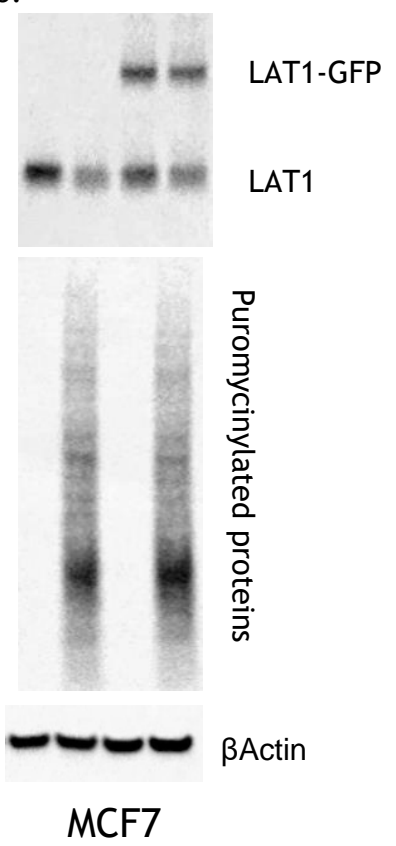

$\mathrm{F}$

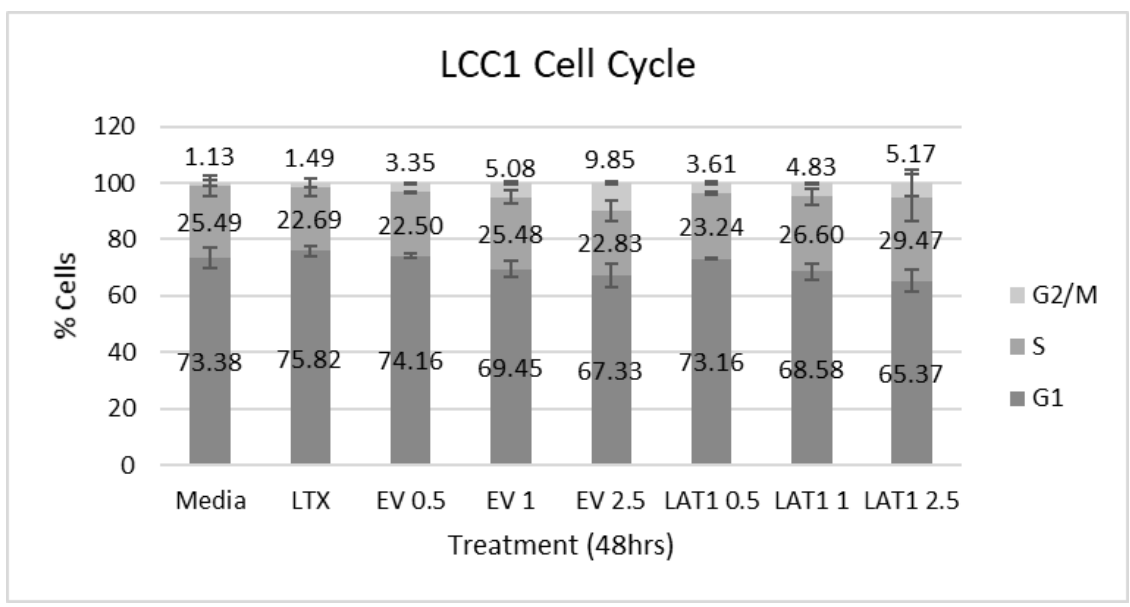


A

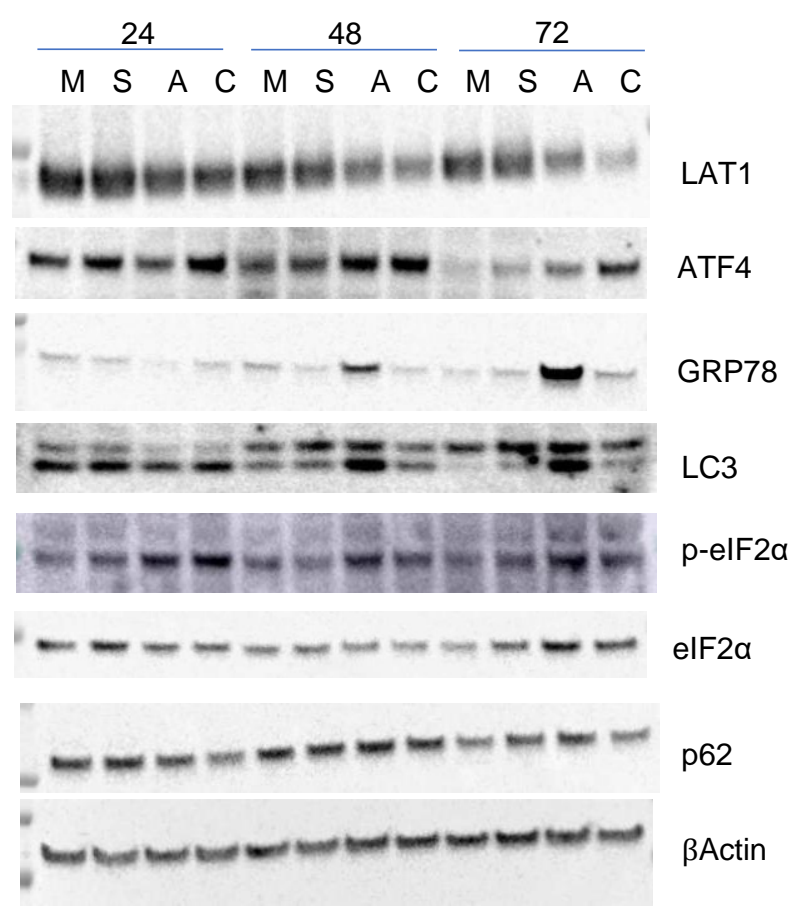

M- media; S- siScramble; A- siA LAT1; C- siC LAT1
B

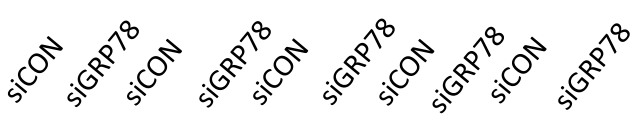

Time: $\begin{array}{lllllllllll}0 & 6 & 6 & 12 & 12 & 24 & 24 & 48 & 48 & 72 & 72\end{array}$

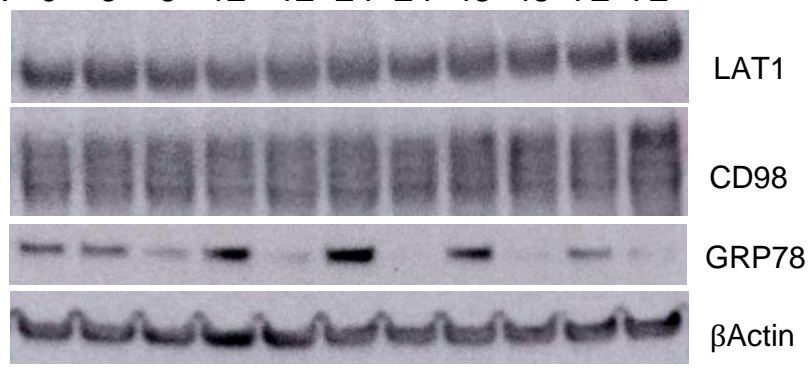

C LAT1 mRNA expression

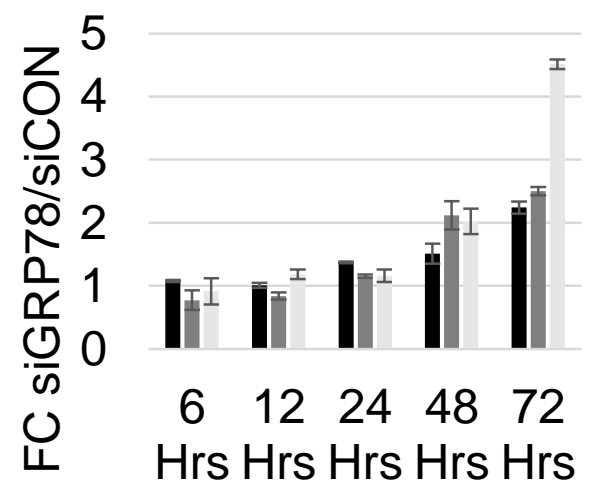

- Replicate 1 - Replicate 2 Replicate 3

Figure 6 
bioRxiv preprint doi: https://doi.org/10.1101/555342; this version posted February 21, 2019. The copyright holder for this preprint (which was not certified by peer review) is the author/funder, who has granted bioRxiv a license to display the preprint in perpetuity. It is made available

Figure 7 under aCC-BY-NC-ND 4.0 International license.

\section{SLC7A5}

GSE2990

$\mathrm{p}=0.007$

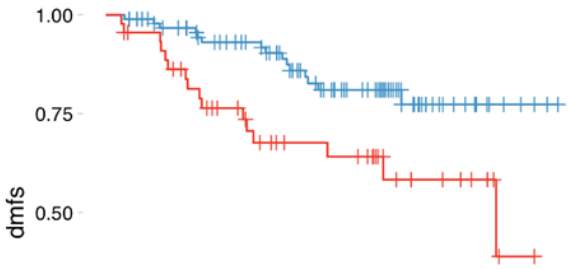

0.25

0.00

$\begin{array}{llr}100 & 150 \\ \text { Months }\end{array}$

\section{GSE6532-p2}

$p=0.037$

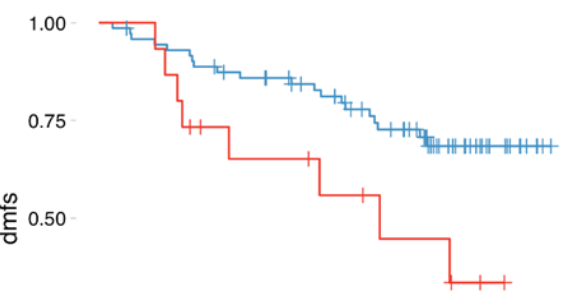

0.25

0.00

$\begin{array}{llcll}0 & 50 & 100 & 150 & 200 \\ \text { Months } & & \end{array}$

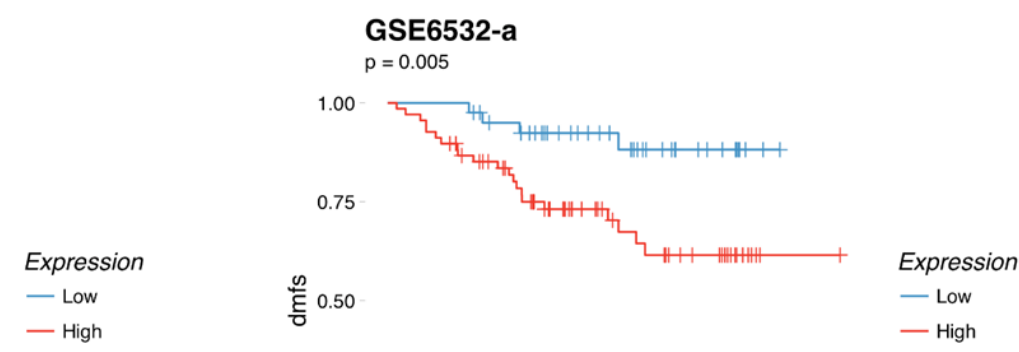

0.25

0.00

0

50 Months ${ }^{100}$

150

\section{GSE9195}

$p=0.01$

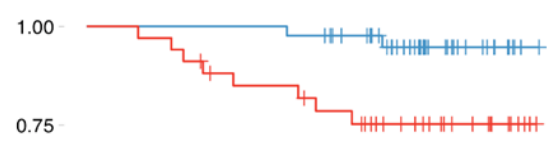

Expression

— Low

- High

$\stackrel{\mathscr{N}}{\text { है }} 0.50$

Expression

- Low

- High

0.25

0.00

$\begin{array}{lll}50 & \\ & \text { Months }\end{array}$


bioRxiv preprint doi: https://doi.org/10.1101/555342; this version posted February 21,2019 . The copyright holder for this preprint (which was not certified by peer review) is the author/funder, who has granted bioRxiv a license to display the preprint in perpetuity. It is made available under aCC-BY-NC-ND 4.0 International license.

\section{Supplemental Figure 1}

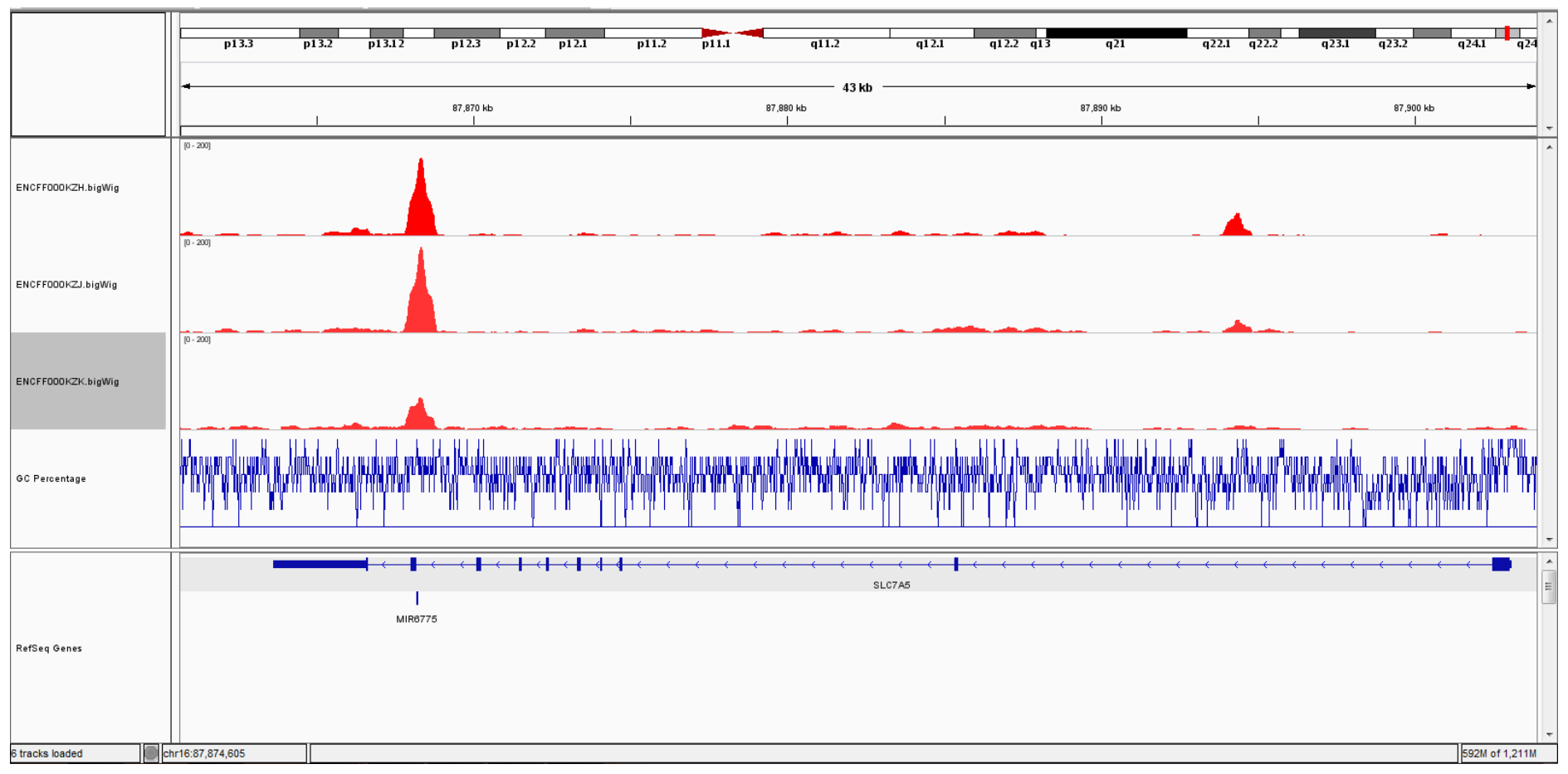


bioRxiv preprint doi: https://doi.org/10.1101/555342; this version posted February 21, 2019. The copyright holder for this preprint (which was not certified by peer review) is the author/funder, who has granted bioRxiv a license to display the preprint in perpetuity. It is made available under aCC-BY-NC-ND 4.0 International license.

\section{Supplemental Figure 2}

A

70.

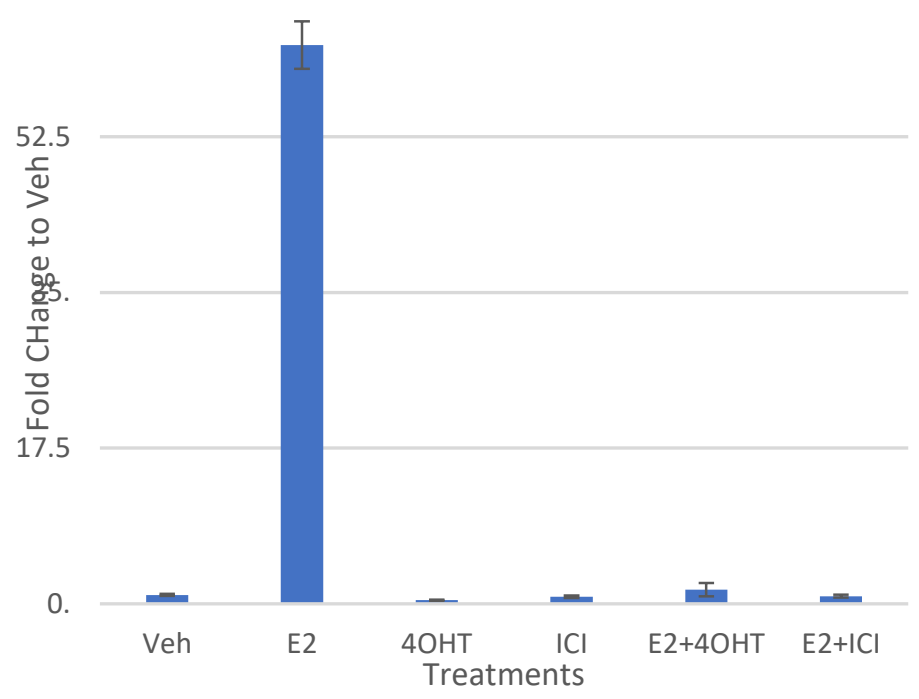

B

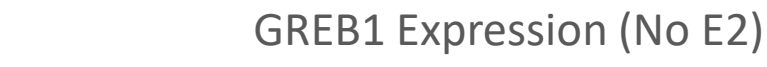

3.

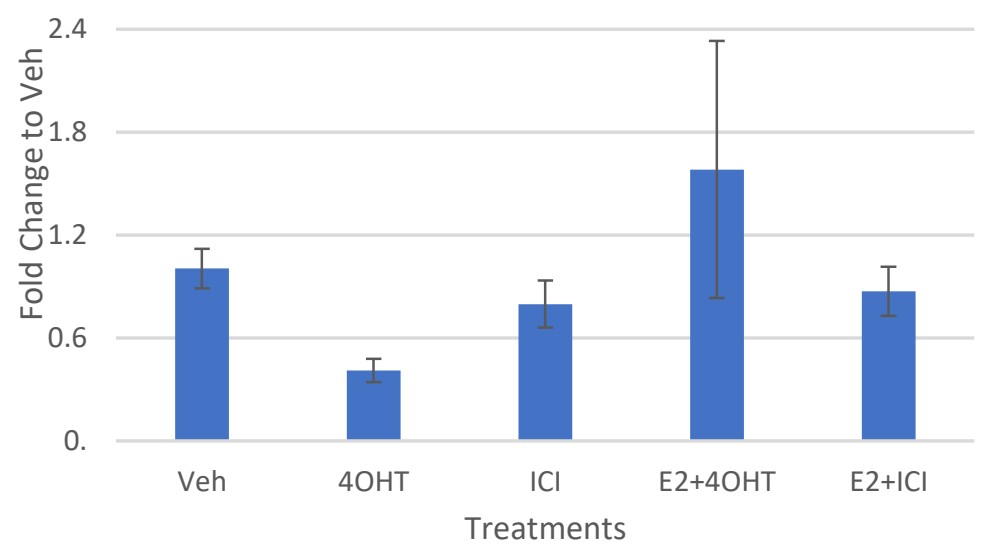

C

LCC9 mRNA Expression

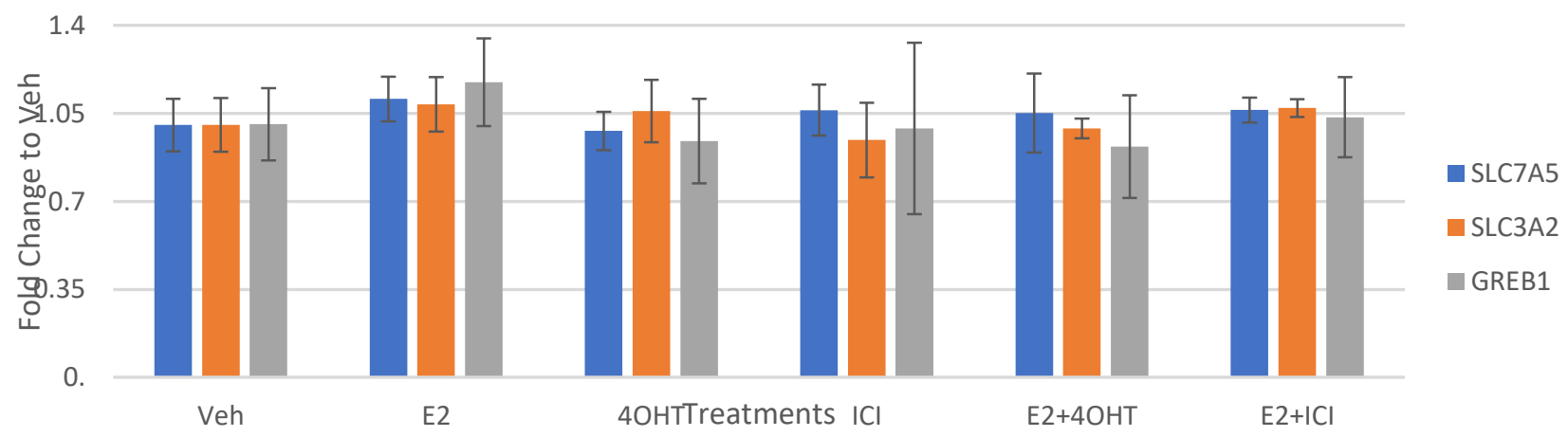



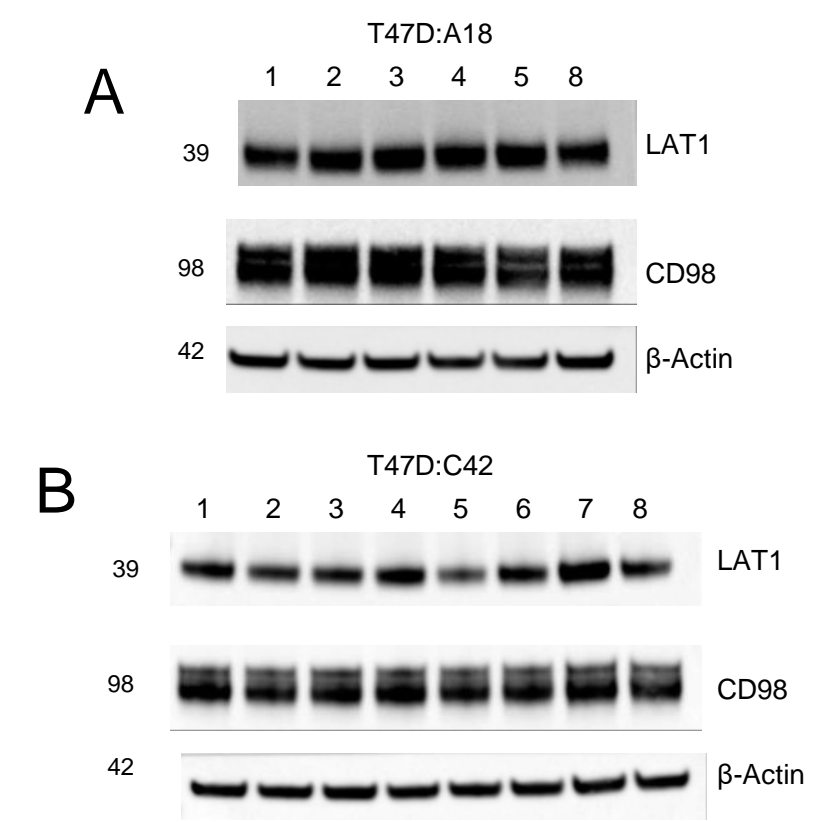

C

39

98

42

T47D:4HT

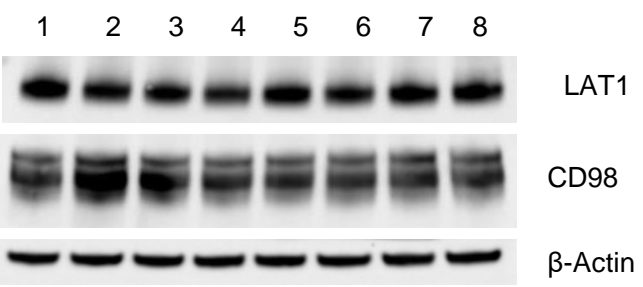

1- Ethanol,

2- 1nM 17- $\beta$-Estradiol (E2),

3- 500nM 4-OH-Tamoxifen (Tam),

4- 500nM Fulvestrant (ICl),

5- $\mathrm{E} 2$ + Tam, 6- E2 + ICI,

7- Tam + ICI, 8- E2 + Tam + ICI

\section{Supplemental Figure 3}




\section{Supplemental Figure 4}

A

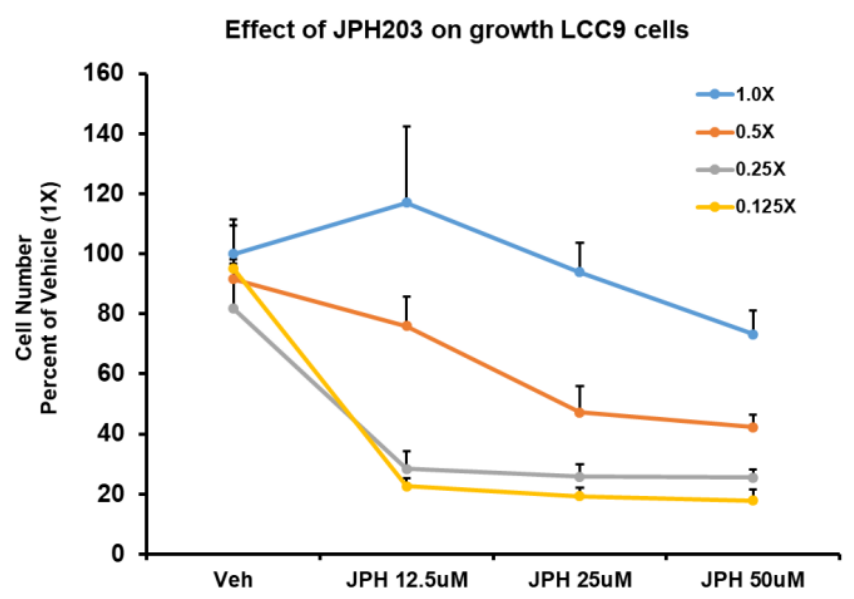

C

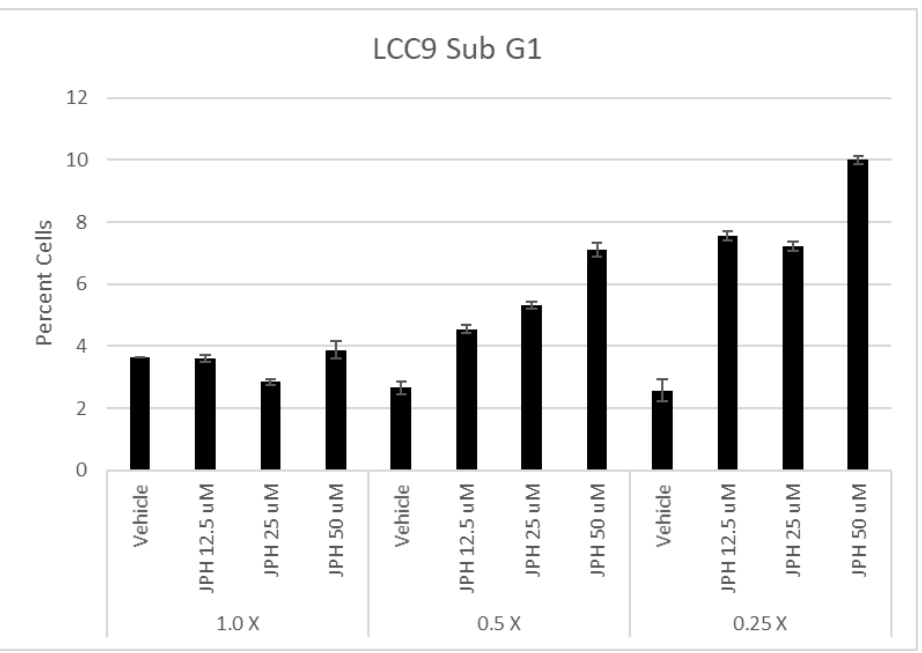

E
B

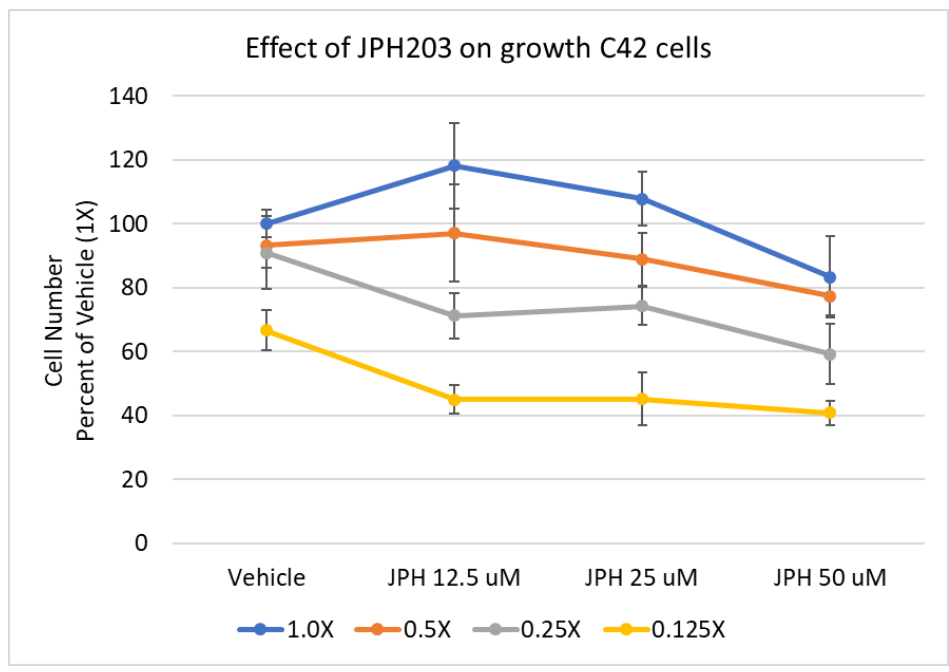

D

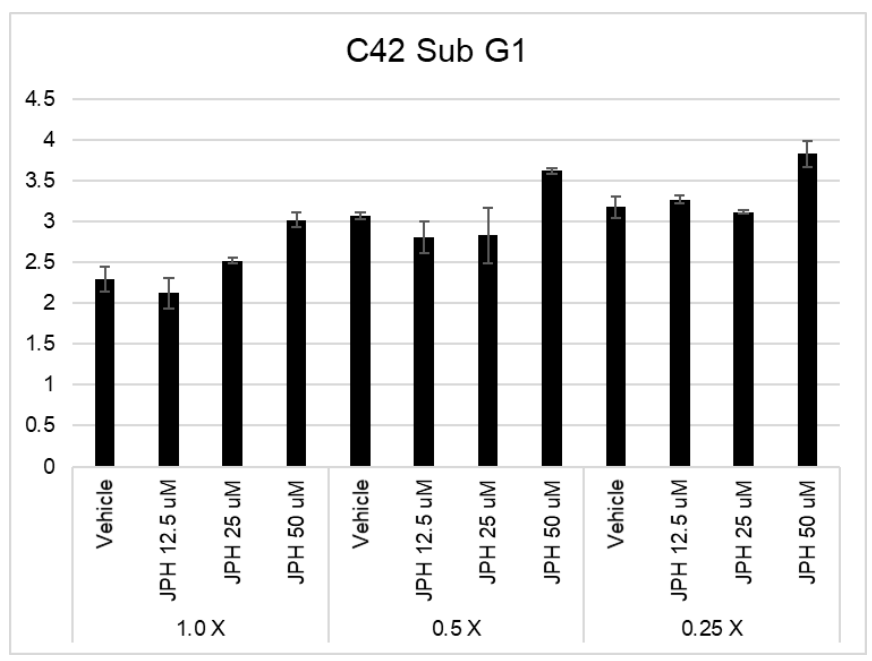

F
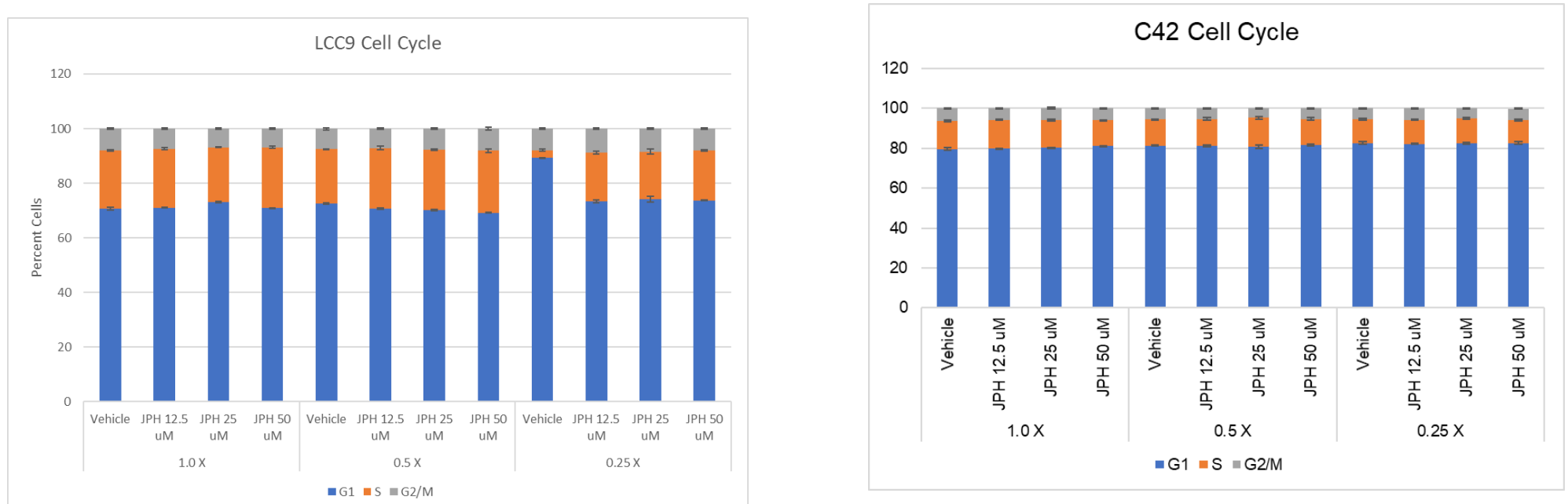
223441 at

226301 at

1555953 at
2211575 . at

209776 s at

225491_at

208389.5 at
$212811 \times$ ×at

212810 s at
$209610 \leq 5$ at

230494_at

218675 at
223194 s at

223194,5 at
1561093 at

205507_at

57588 at

29090 at
210010 . at

2118555 s at

220474_at

226010 at
225212 at

2252120 at
25355
25505

225306 s at
200030 sat

20030 sat

221020.5 at
2232956 at

201917 s_a

201918 at

217961 at

227012 at
205715 at

32091 at

212683 at

200657 at

212085 at
2225959 at

224963

205769 at

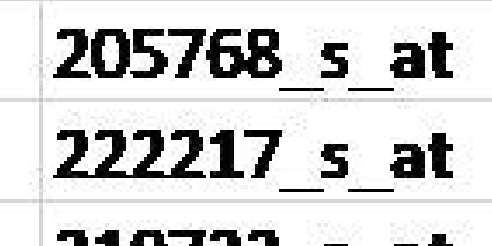

219932 at

219344at
201250 s at

201250 . 5 at
212024 sat

1558540 s at
1555500 s.

218994 sat

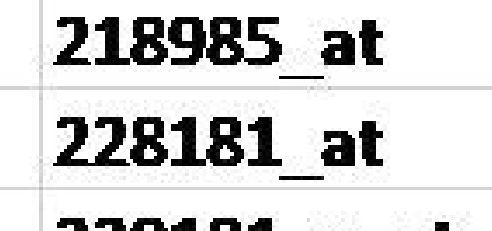

220181 Xat
226501 at

202614 at

203971 at

203306 s 5 at
209326 at

206770_sat

202583 at at

225882 at

$219447 \mathrm{~s}$ at

225037 at

2313083 at

218988 at

225872 a

213119 at

234978 at
218928
s at

218928 s at

224580 at

218237 .5at
22459 at

224579 at

228951 at
56821 at

218727_at

235241 at

221110 at
223917 s at

223917. 5 at

2020858 at
155460 at
1555551 s. at

1556551 s. at

209267s at

2198695 sat
$200924 s$ at

225570 at

223798 at
235299 at

243894 at

2245959 at

224595 at

2224609.at

228212 at
1558703 at 219525 at

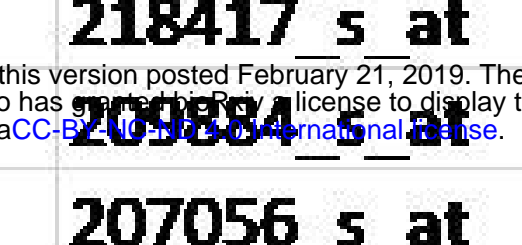

207056 sat

282155
228935
2019
2015

$218151 \times$ at

$218151 \times$ at
222155 sat
22305 at

228236 at

219795 at
22383 at
20254 at

210854 $x$ at

202119at at

212295 s at

207528.5

277678 at

201195_sat

229153 at

232057 at

203909 at

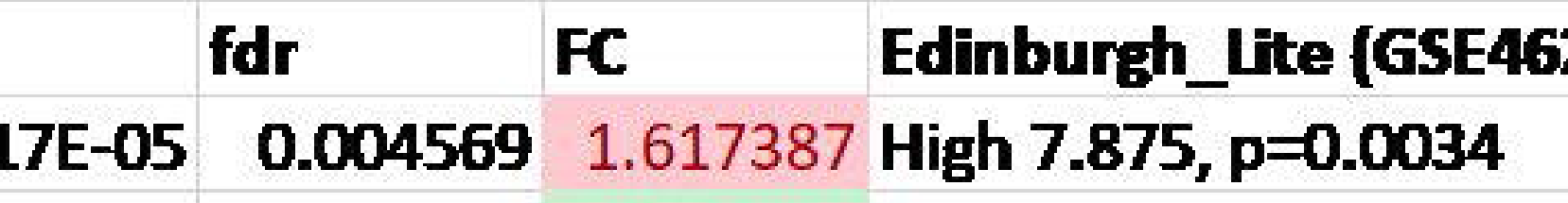

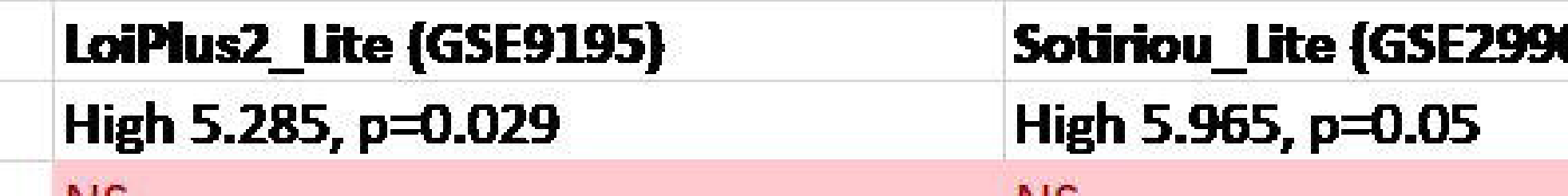

Ns

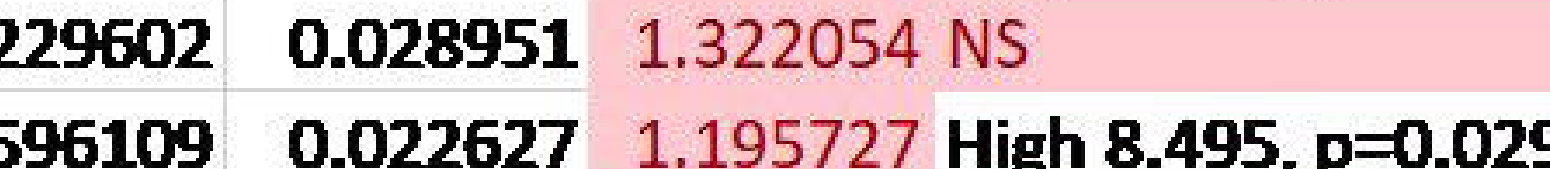

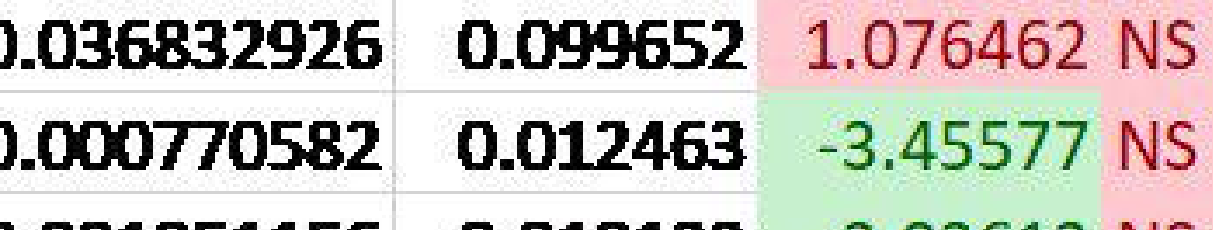

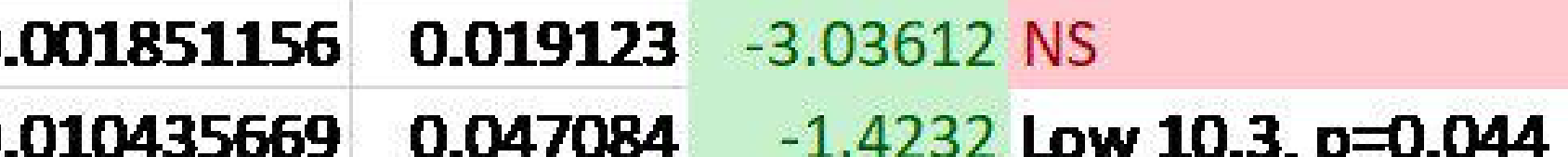

$0.07289470 .0385277-1.14875$ NS $10.3, \mathrm{p}=0.041$

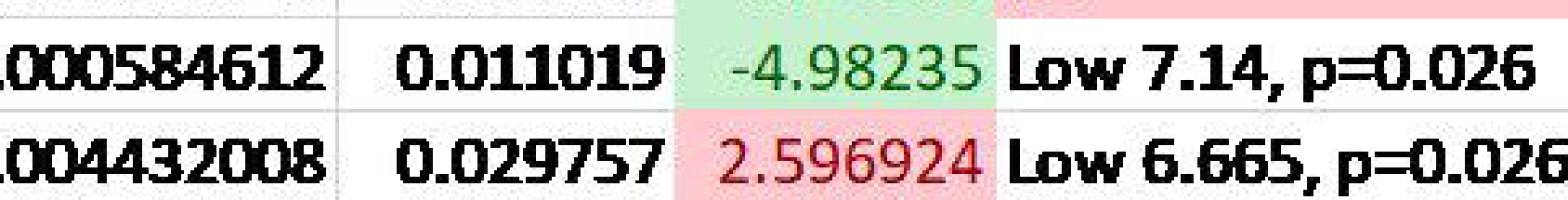

0.000199780 .0006101 .1550061 Low $8.485, p=0.043$

$\begin{array}{lll}0.15973788 & 0.038257 & 1.339344 \text { Low } 6.099, p=0.046 \\ 0.05907 & 1.486868 \text { Low } 5.305, p=0.093\end{array}$

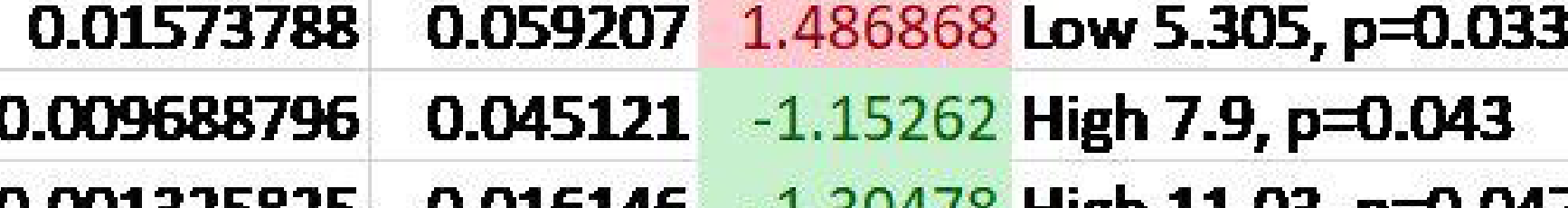

$0013258250.016146-1.30478$ High 11.03, $p=0.047$

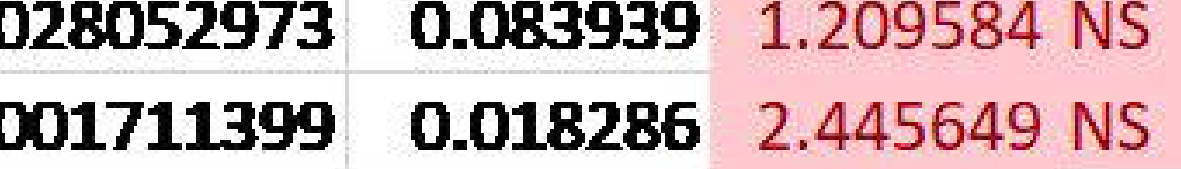

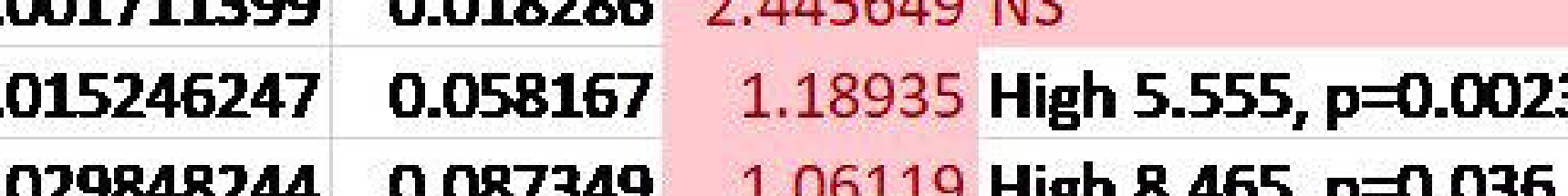

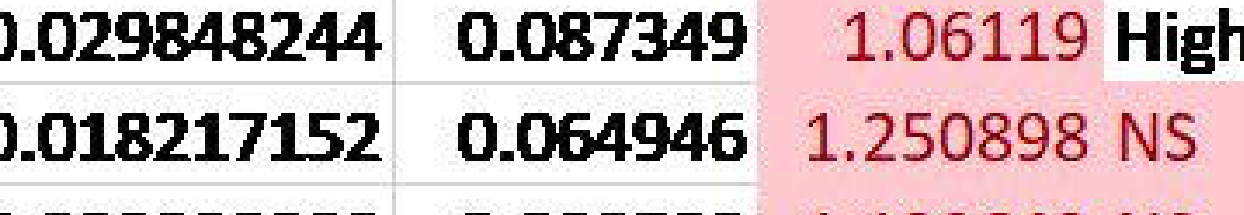

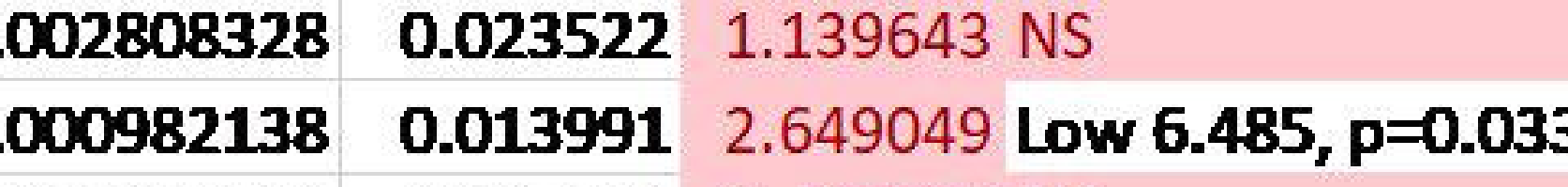

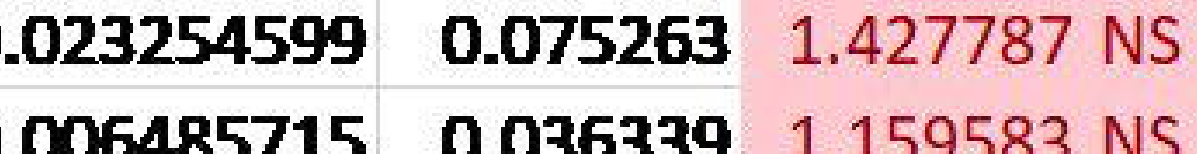

$\begin{array}{lll}0.037848284 & 0.101473 & 1.209032\end{array}$

0.0274529
0.087748
0.091085

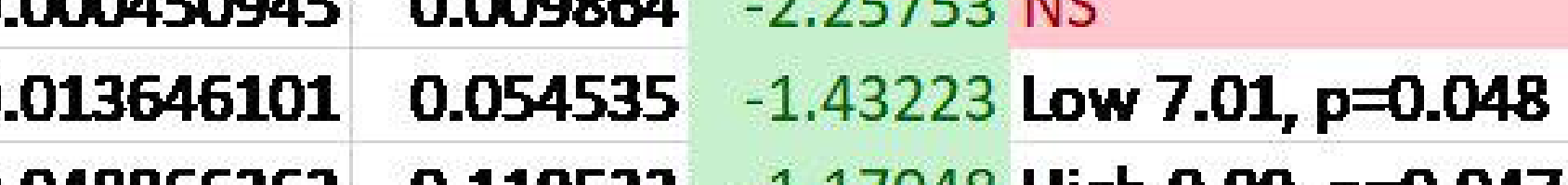

048865263
0.119523
-1.177048 High $9.99, p=0.047$

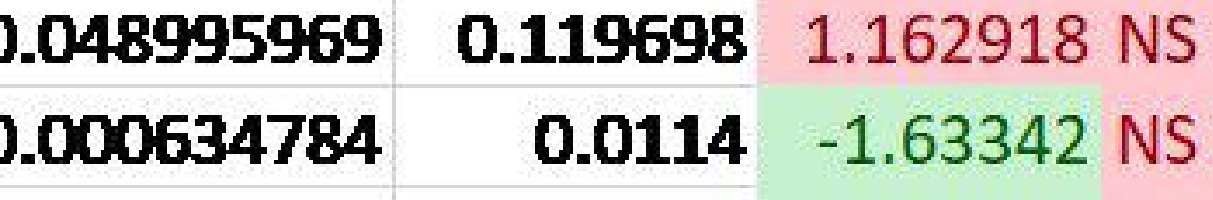

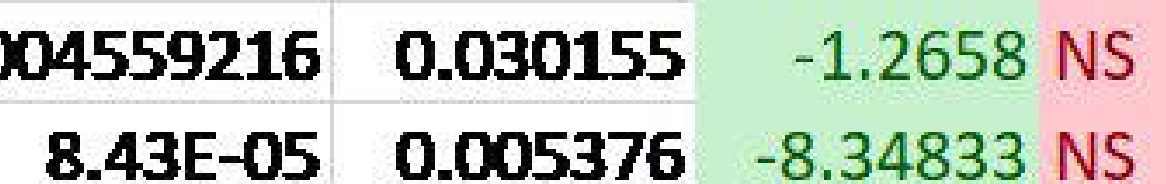

$\begin{array}{llll}0.00931476 & 0.013575 & -14.2258 \text { NS }\end{array}$

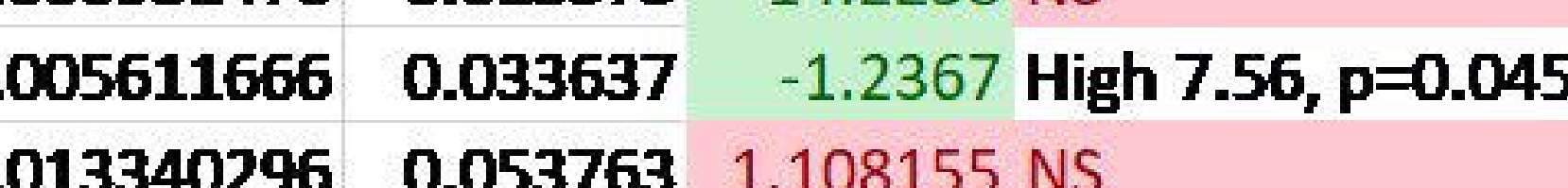

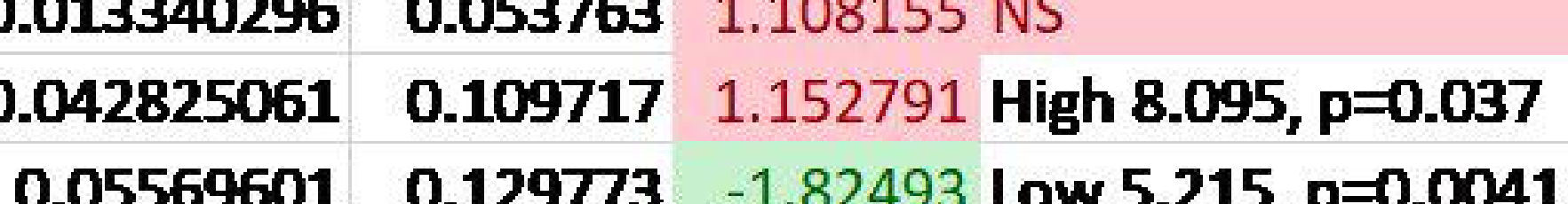

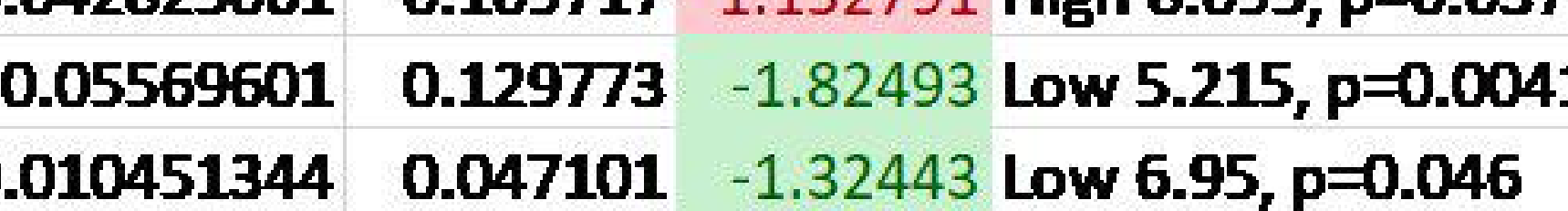

(1)

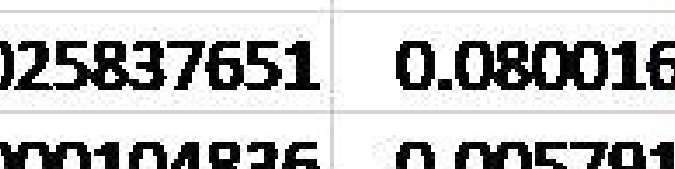

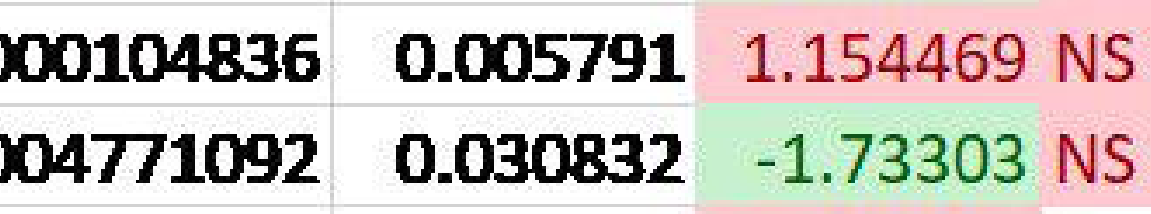

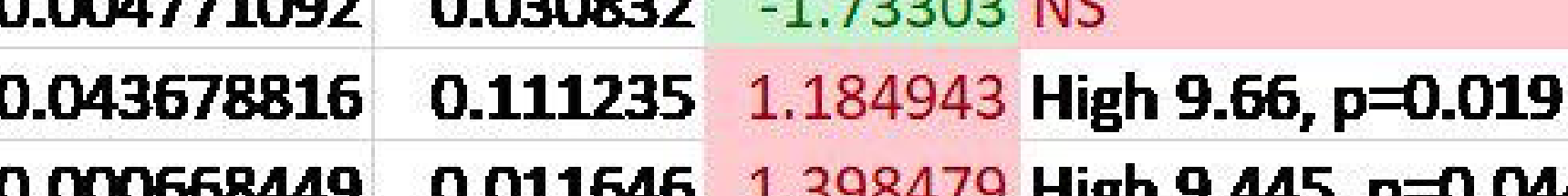

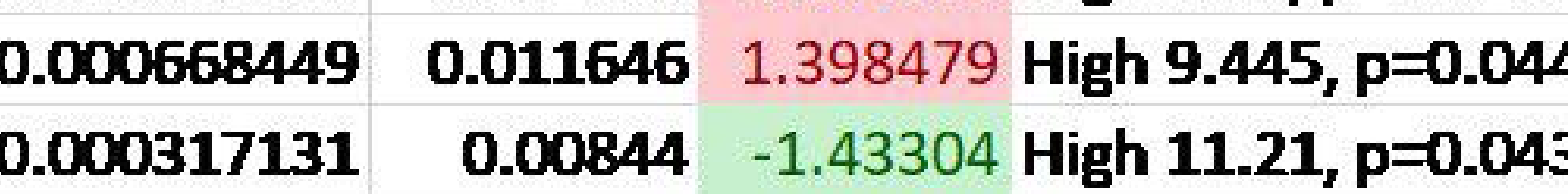

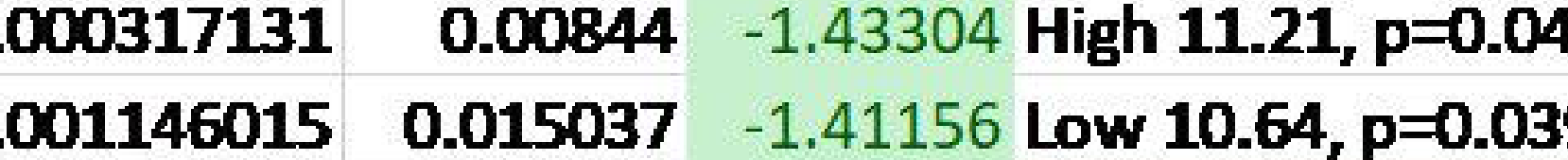

$\begin{array}{llll}0.001805146 & 0.018832 & -1.60159 \mathrm{NS} \\ 0.05111948 & 0.032069 & 1.247872 \mathrm{NS}\end{array}$

$\begin{array}{ll}0.40589996 & 0.106292 \\ 1.091067 \text { NS }\end{array}$

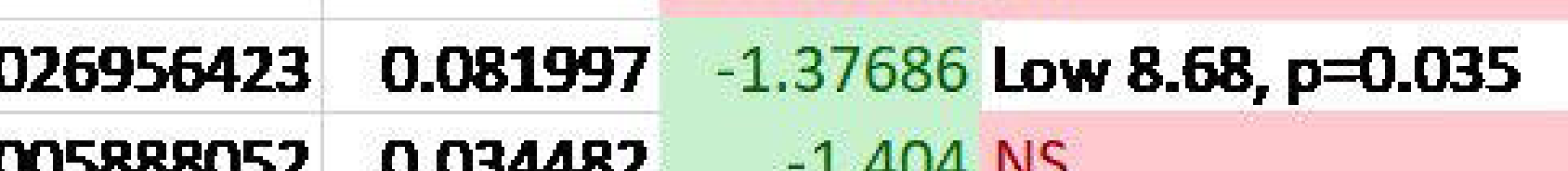

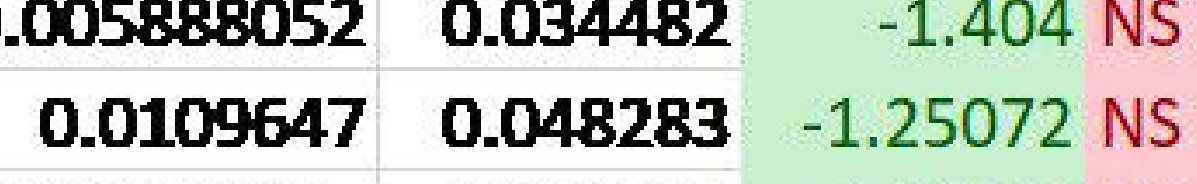

$\begin{array}{llll}0.00470427 & 0.028784 & -1.1 .19602 \mathrm{NS} \\ 0.006823705 & 0.037259 & 1.072196 & \mathrm{NS}\end{array}$

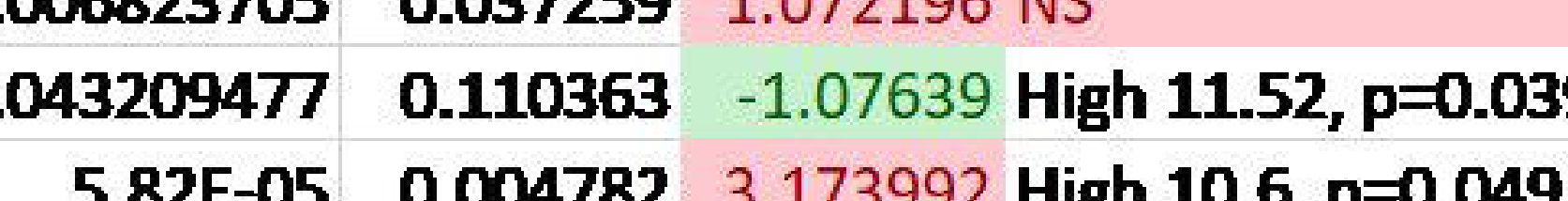

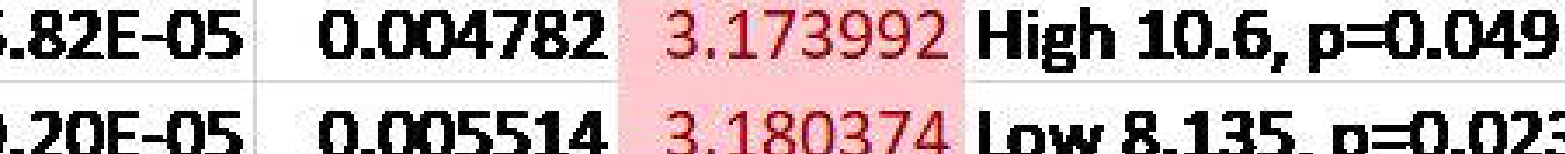

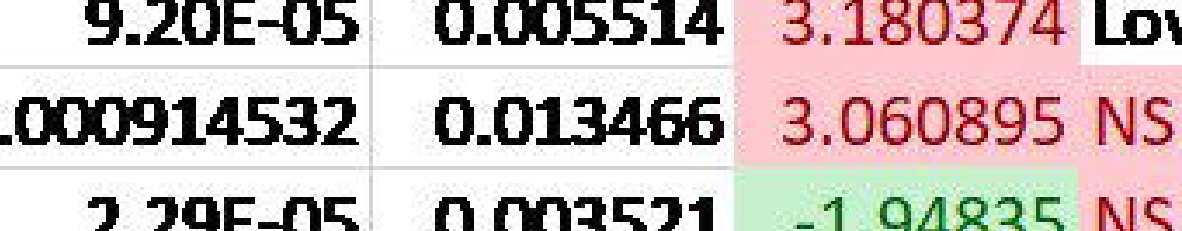

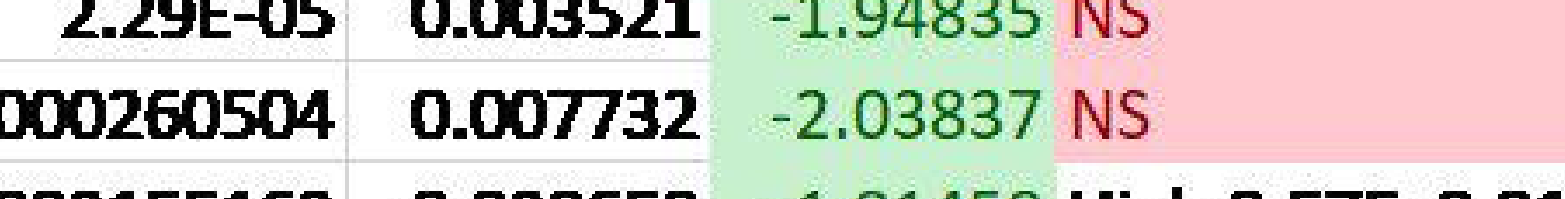

(1)

$\begin{array}{lll}0.001001026 & 0.014165 & -2.22383 \\ 0\end{array}$

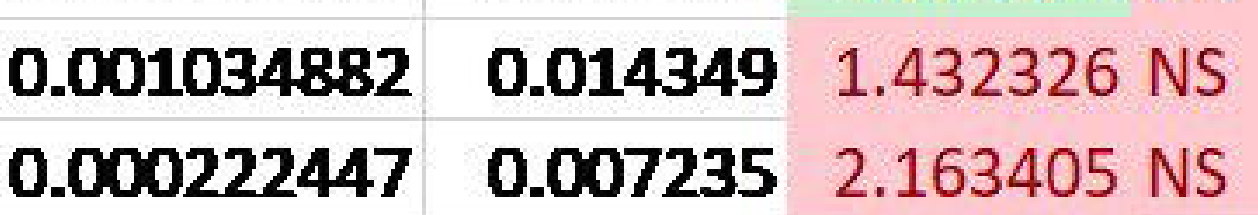

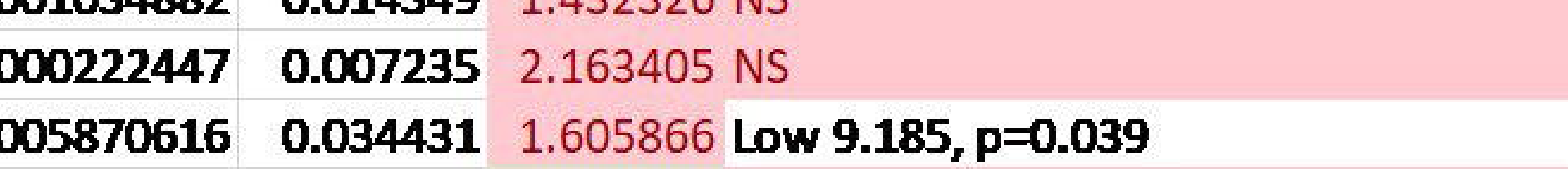

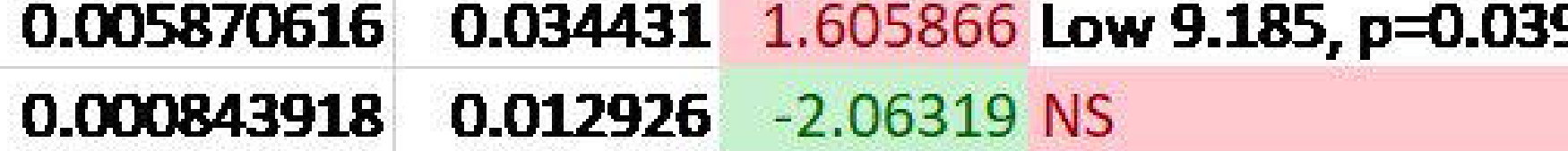

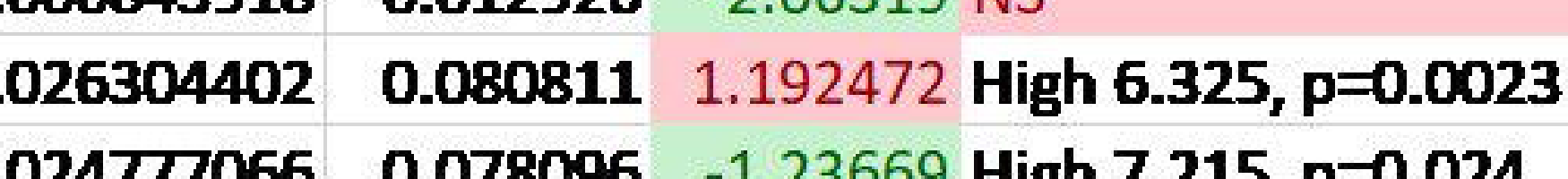

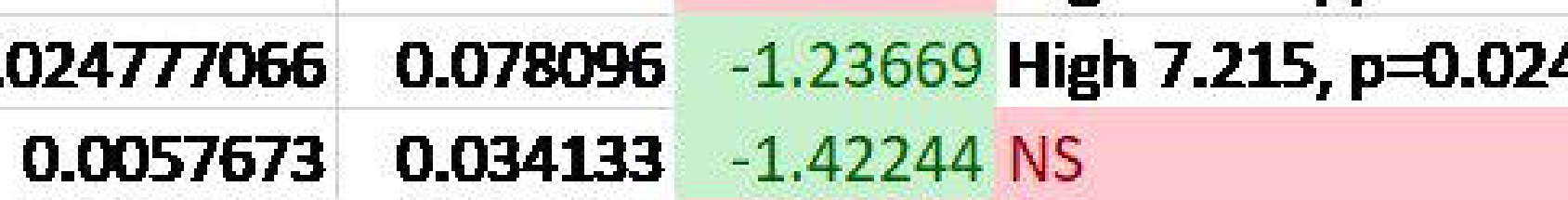

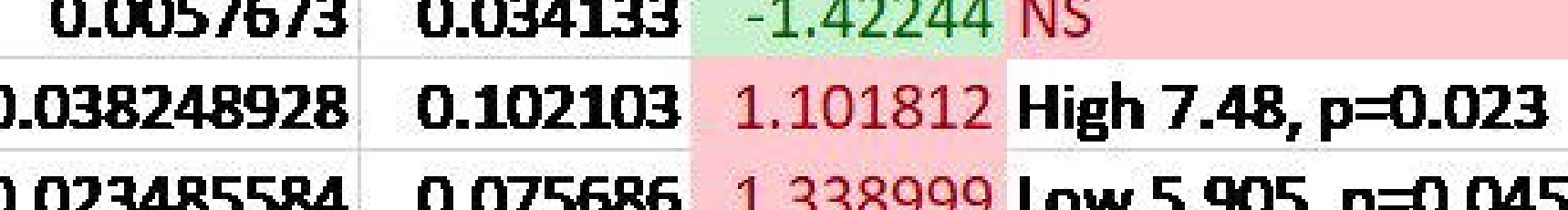

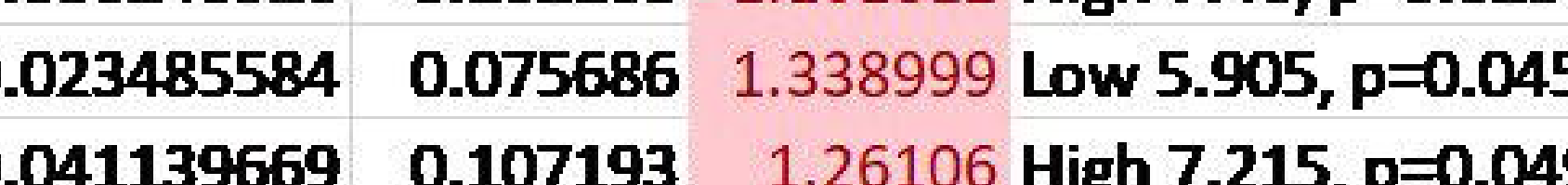

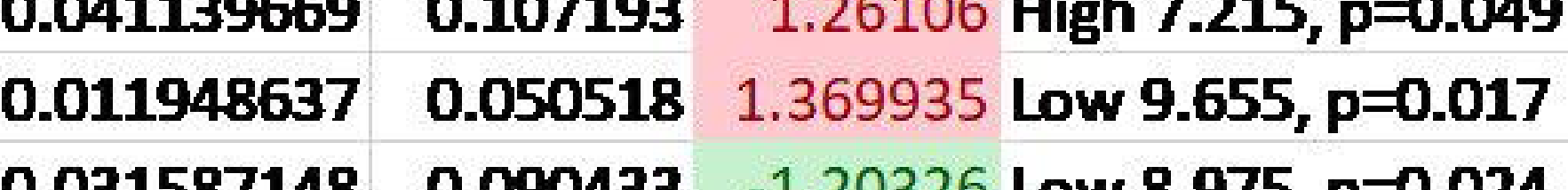

0.031587148 0.090433 -1.20326 Low $8.9975, p=0.0 .024$

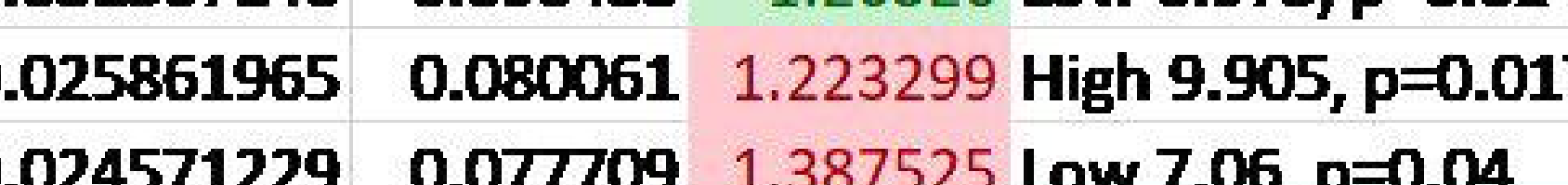

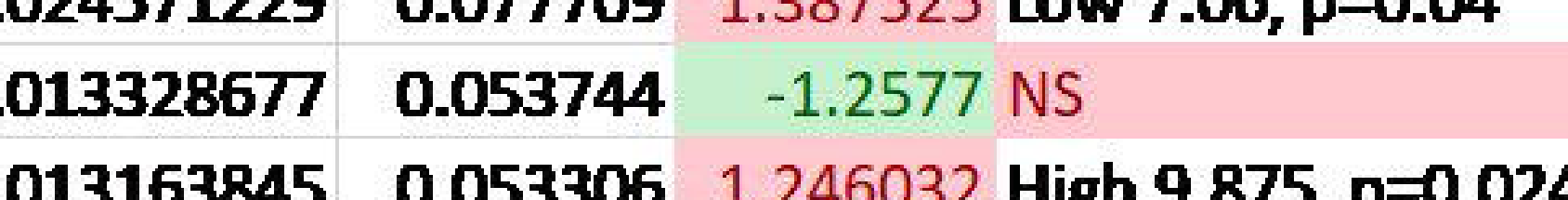

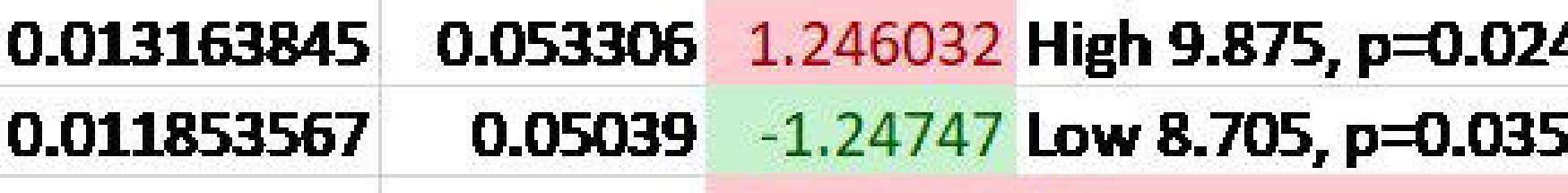

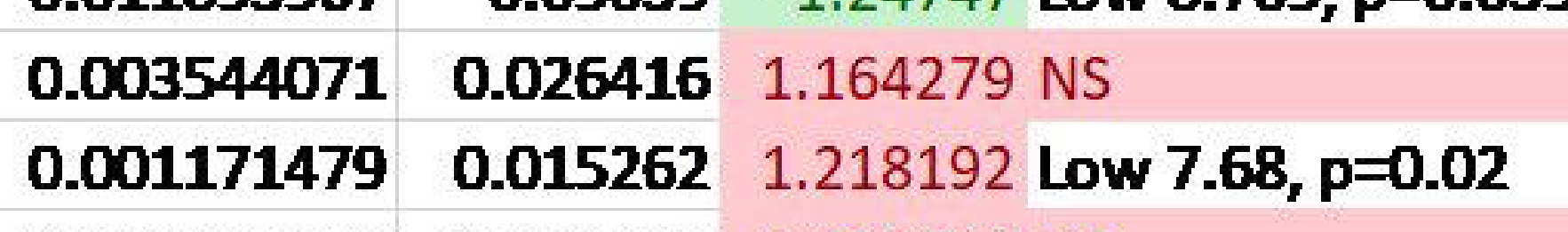

$\begin{array}{llll}0.008323727 & 0.040955 & 1.201619 \mathrm{NS} \\ 0.00211897 & 0.020497 & 1.145549 & \text { High } 7.195, \mathrm{p}=0.042\end{array}$

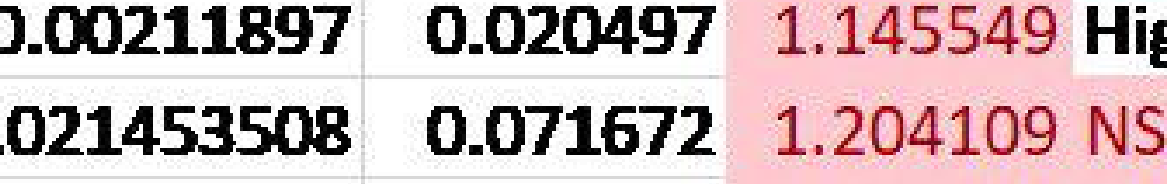

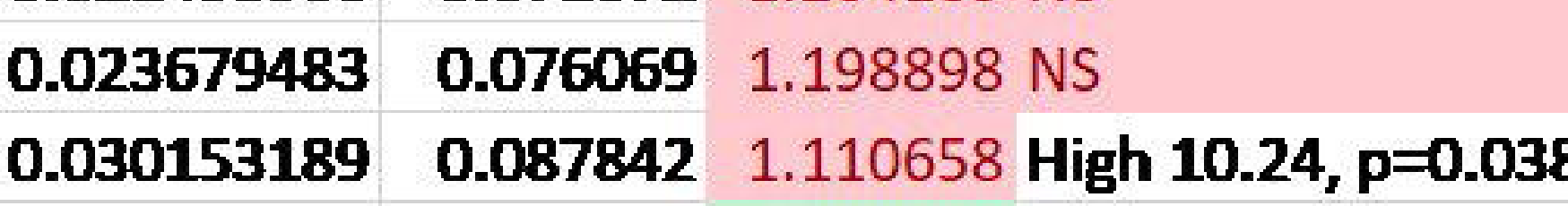

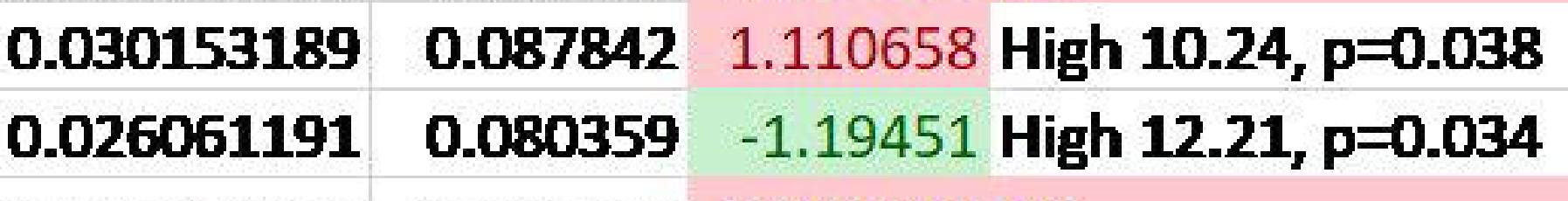

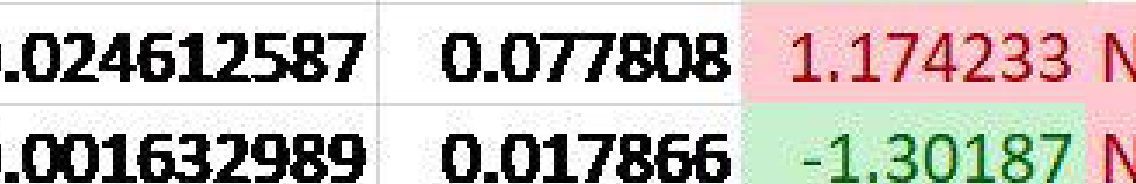

0.0331251760 .093274

$\begin{array}{lll}0.0283179442 & 0.040282 \\ 0.084239 & -11\end{array}$

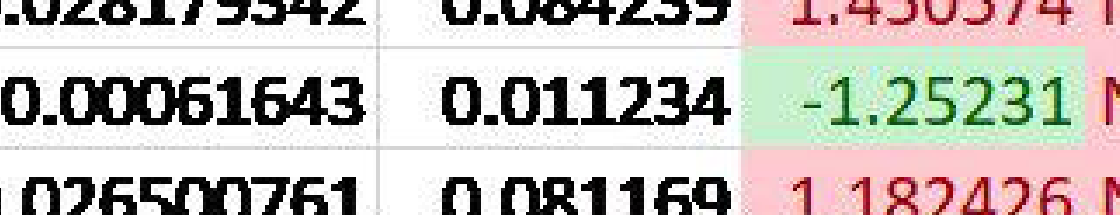

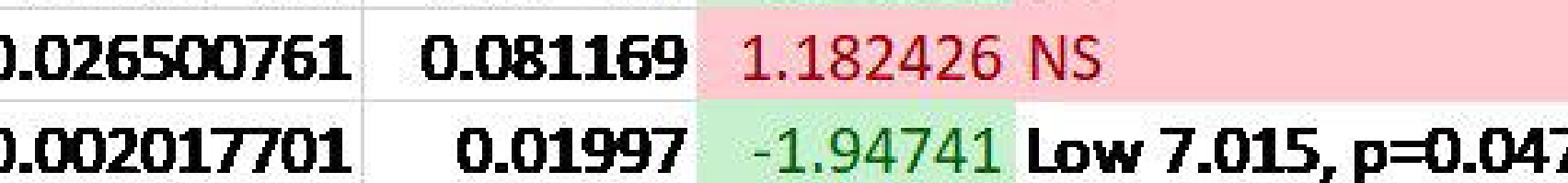

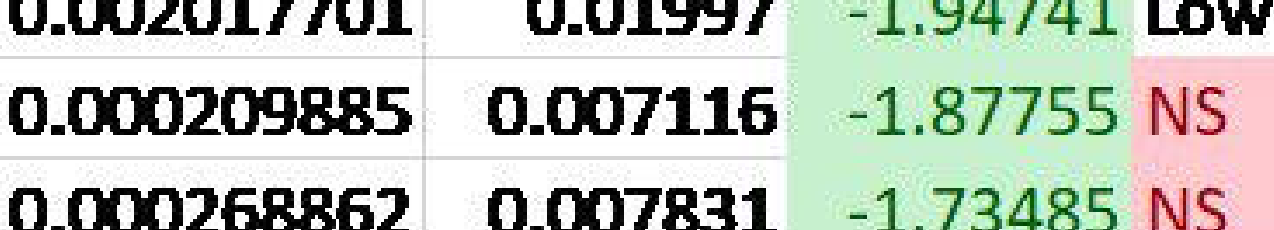

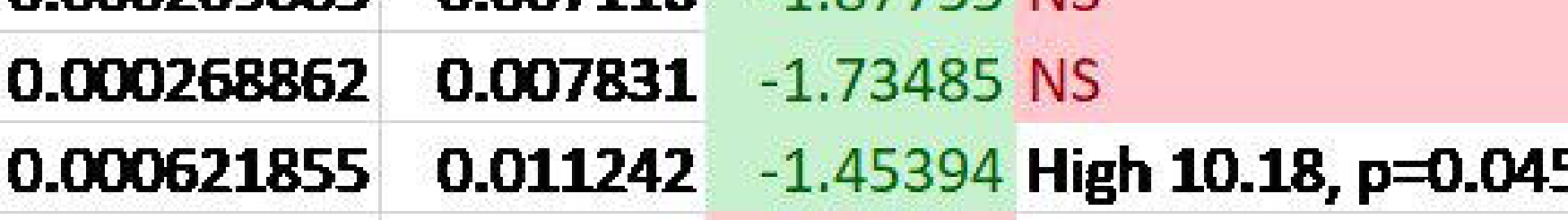

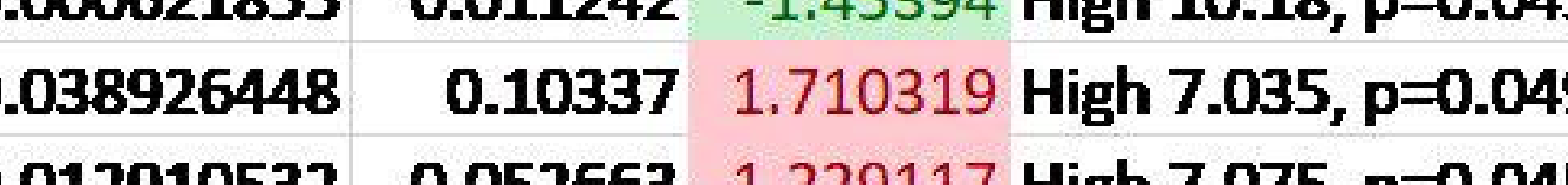

$0.039286120 .100007 \quad 1.37501 \mathrm{NS}$

is

$\begin{array}{lll}0.37494522 & 0.100836 & 1.1252249 \\ \text { Low } 9.605, \mathrm{p}=0.028\end{array}$

$\begin{array}{lll}0.000491043 & 0.010332 & 1.232901 \mathrm{NS} \\ 0.002020268 & 0.023924 & 1.39137 \text { low } 13.02, \mathrm{p}=0.039\end{array}$

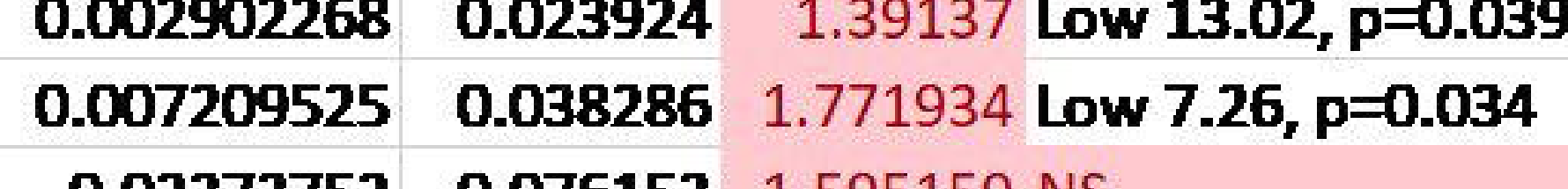

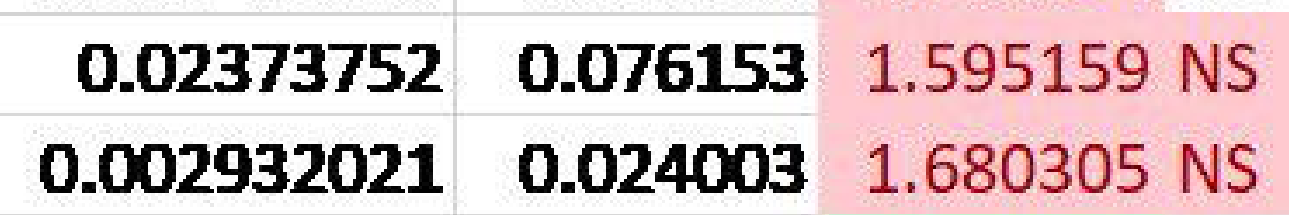

8.35E-05 0.005357 .2 .39285 Low $8.27, \mathrm{p}=0.043$

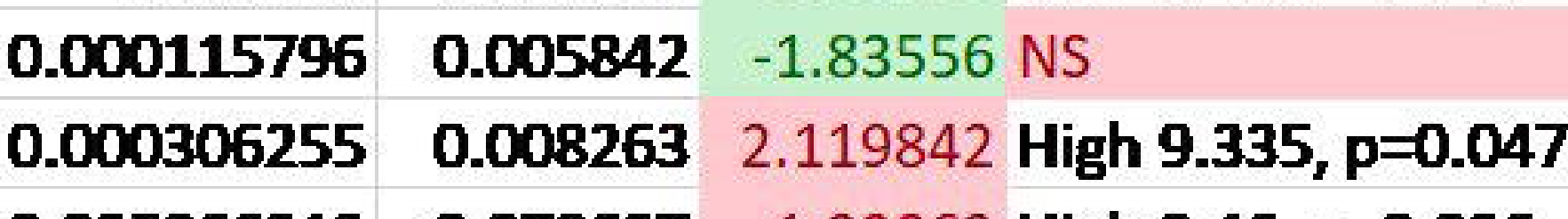

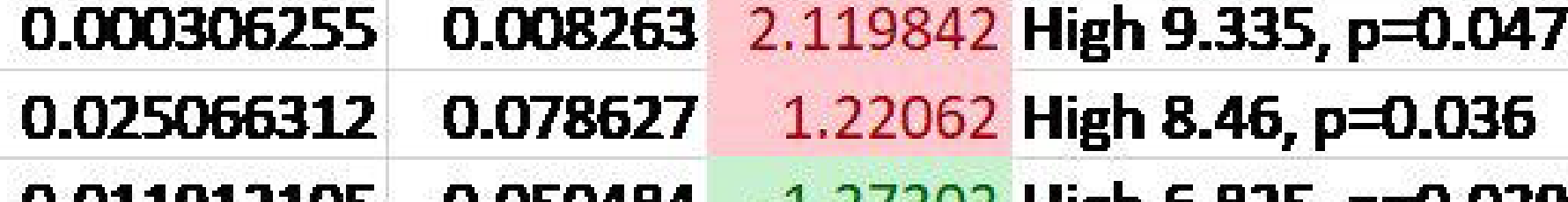

$0.0119121050 .0050044-1.37303 \mathrm{High} 6.8 .85, \mathrm{p}, \mathrm{p}=0.0 .039$

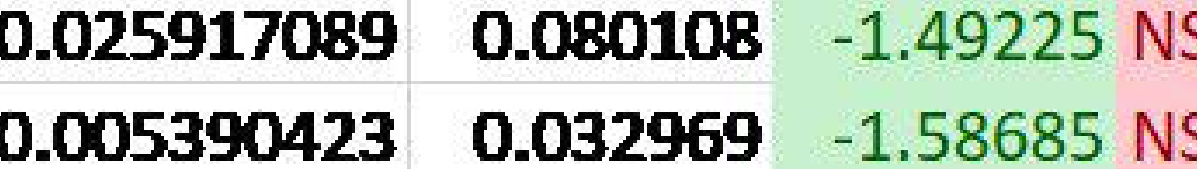

0.032554917
0.0 .0292145
0.1 .303585 Low $10.48,00.036$

$\begin{aligned} & .0110888324 \\ & 0.0485544\end{aligned}-1.39633$ Nigh 7.505 , p=0.049

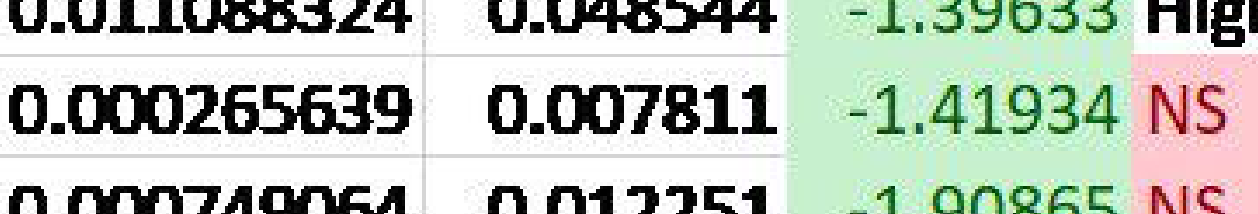

$\begin{array}{llll}0.000749064 & 0.012251 & -1.90865 \mathrm{NS} \\ 0.04537939 & 0.11378 & -1.18868 \mathrm{NS}\end{array}$

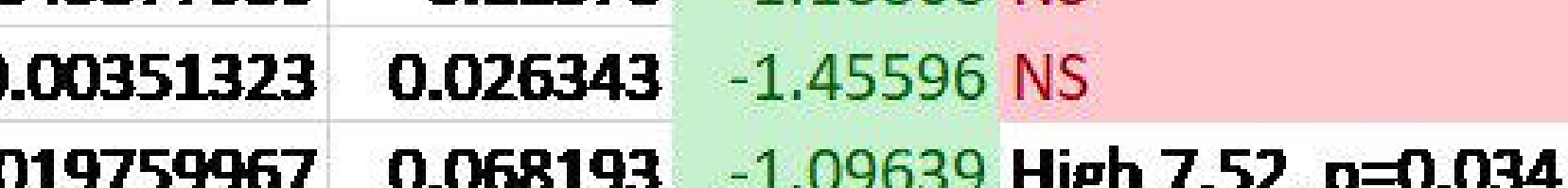

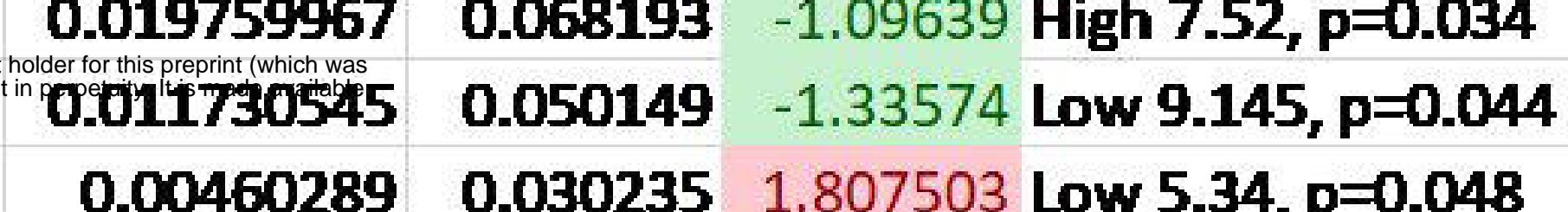

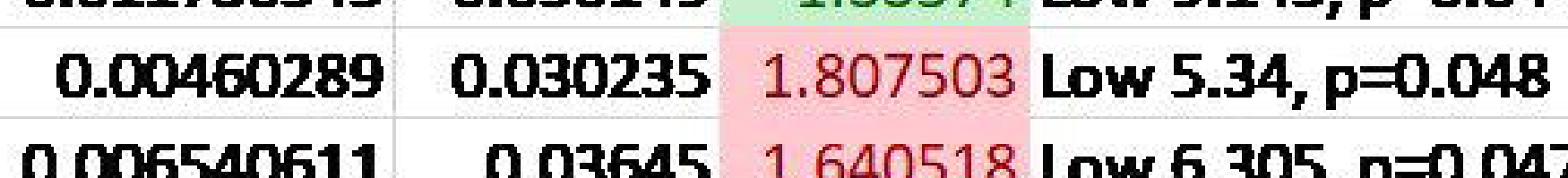

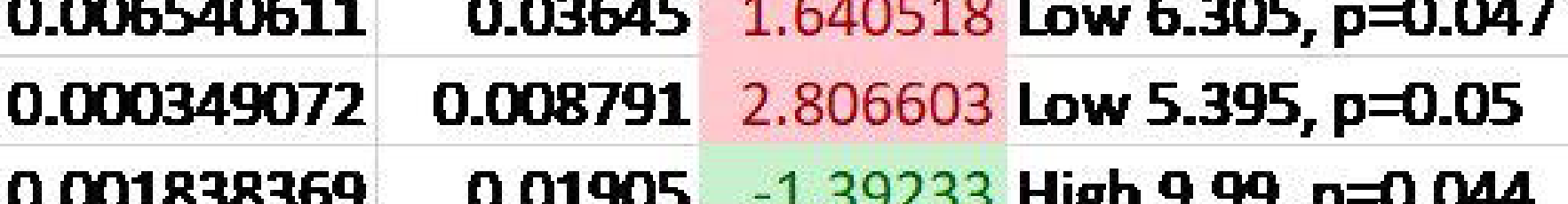

$0451207360.113401 \quad 1.125244$ High $9.435, p=0=0.045$

$0.0072177380 .038296 \quad 1.1477351$ High $7.755, p=0=0.0075$

$0.0377088970 .010273-1.84169 \mathrm{High} 5.78, \mathrm{p}=0.037$

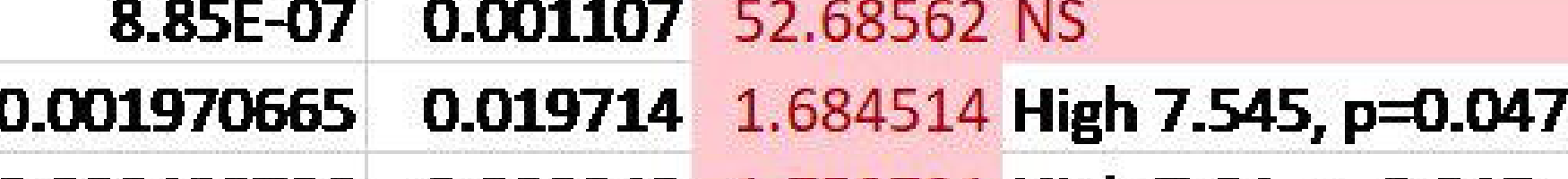

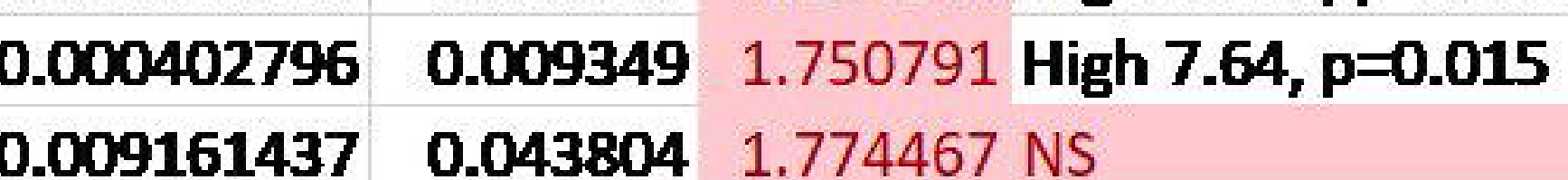

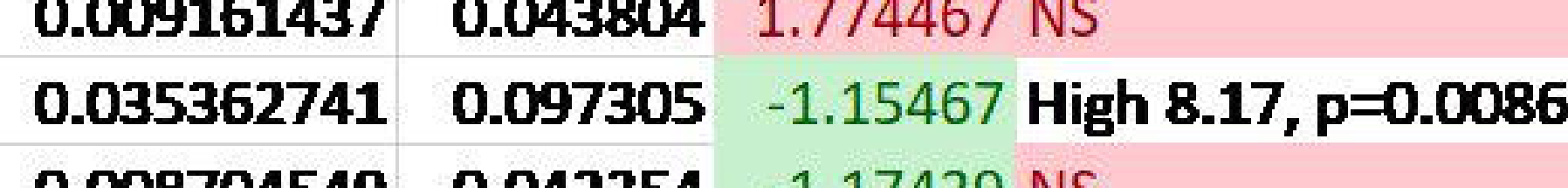

$\begin{array}{llll}0.008704549 & 0.042354 & -1.17439 \\ 0.00027211 & 0.007883 & 2.733138 \\ 0.0 w 5.095, p=0.04\end{array}$

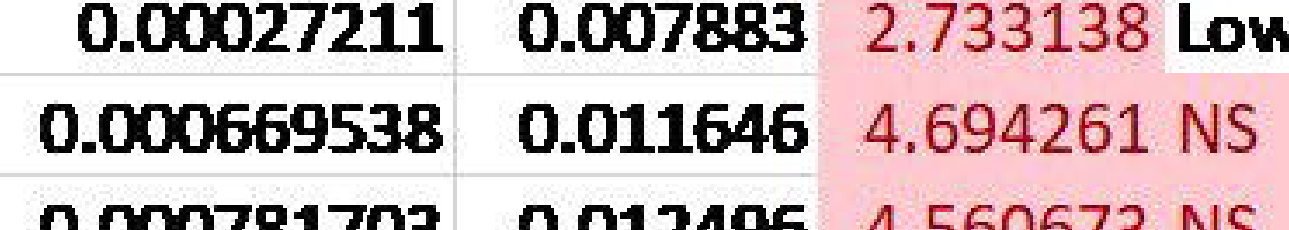

$0.0668655160 .037362 \quad 1.674611$ Low 11.21, $\mathrm{p}=0.046$

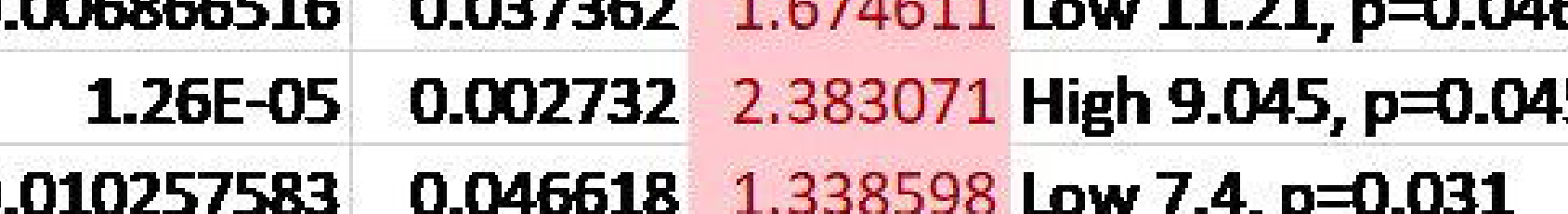

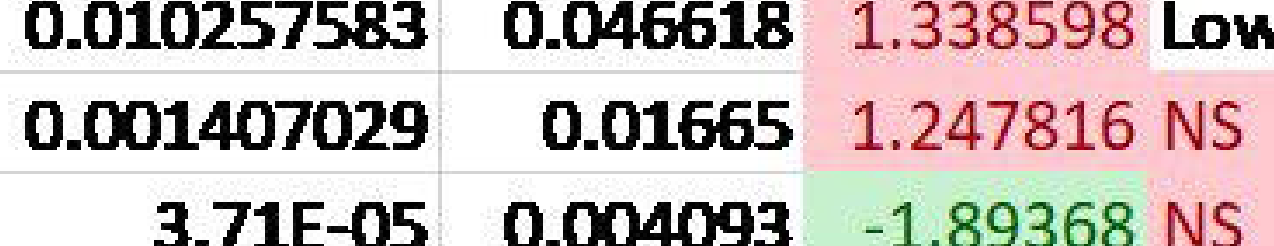

$\begin{array}{llll}0.000618752 & 0.011242 & 5.247237\end{array}$

0.0065285990 .036416

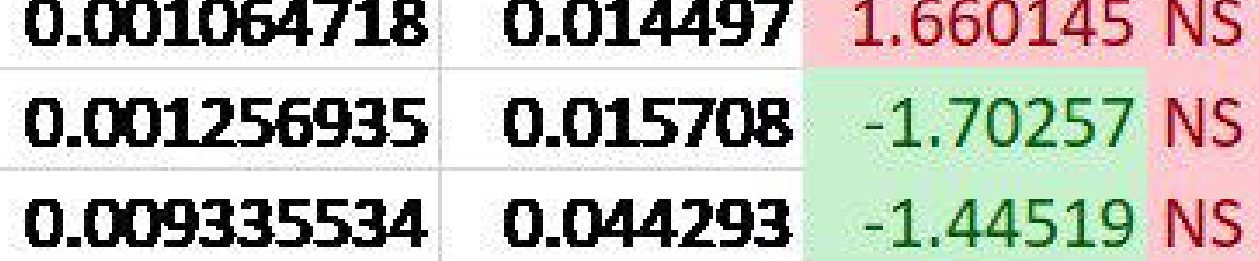

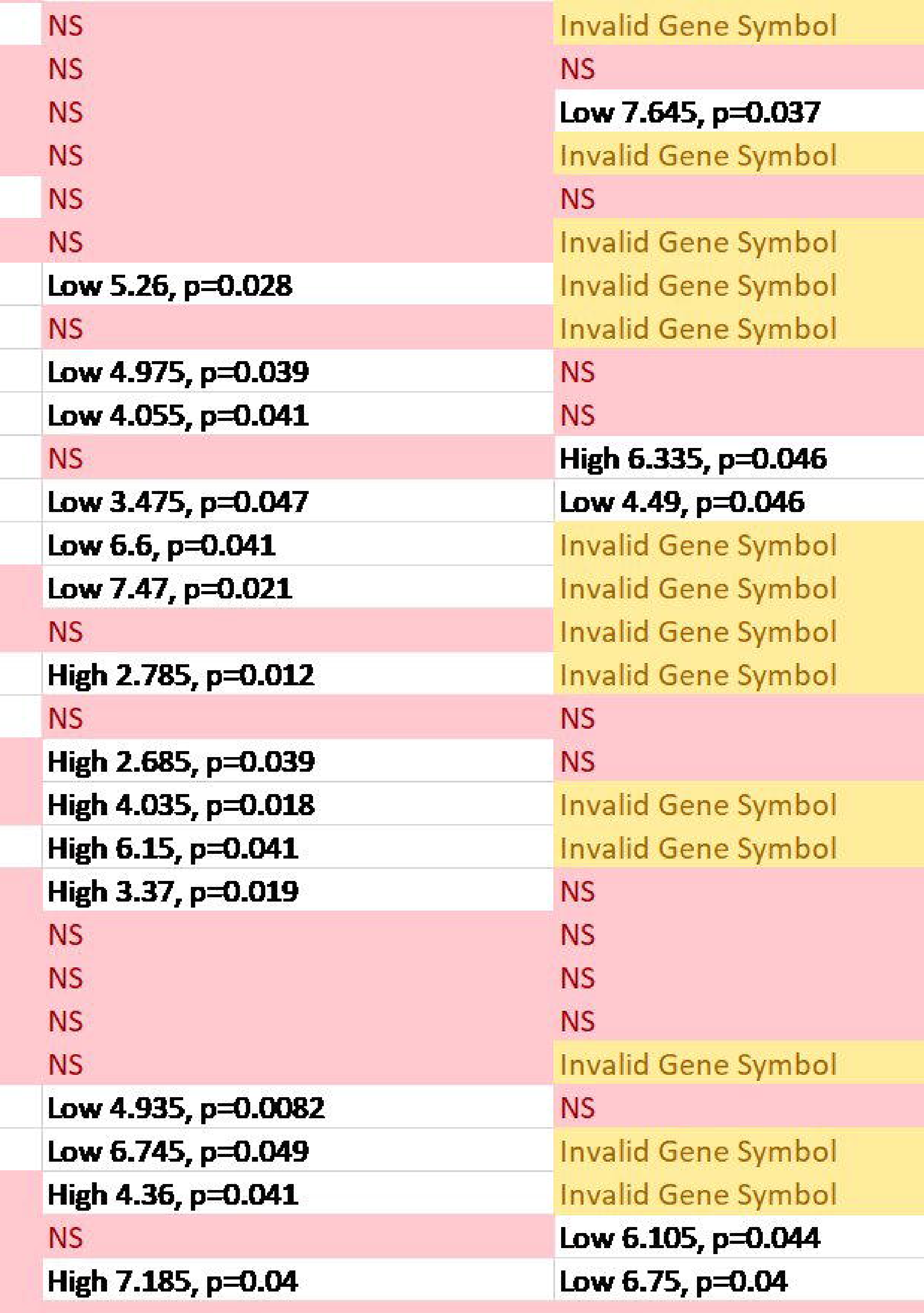

$\begin{array}{ll}\text { NS } & \text { Low 6.105, } \mathrm{p}=0.044 \\ \text { High 7.185, } \mathrm{p}=0.04 & \text { Low } 6.75, \mathrm{p}=0.04\end{array}$ NS

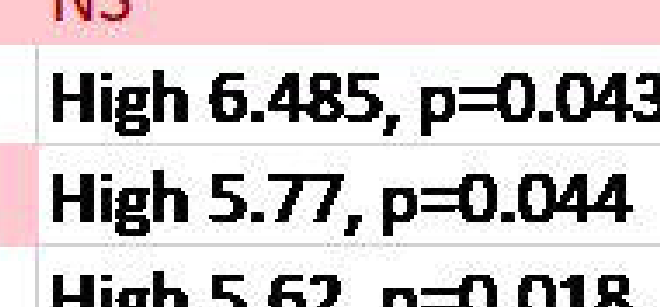

Low 1.88, $=0.0 .027$

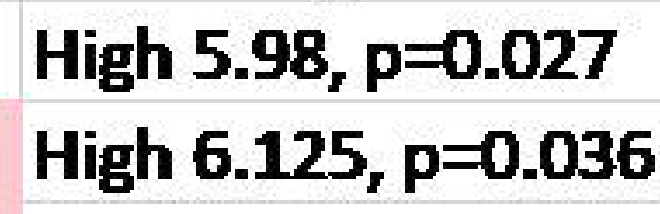

Low 
SLC1A4

SLC1A5

(1A

SLC $3 A 2$

SLC4A1AP

SLC4A2

SLC4A7

SLC5A6

SLC6A6

SLC6A14

SLC7A1

SLC7A2

SLC7A5

SLC7A6

SLC7A6OS

SLC9A1

SLC9A3R1

SLC9A3R2

SLC9A3R2

SLC9A7

SLC9A8

SLC11A2

SLC12A2

SLC12A6

SLC12A7

SLC12A9

SLC16A1

SLC16A3

SLC19A2

SLC22A18

SLC25A1

SLC25A3

SLC25A4

SLC25A5

SLC25A6

SLC25A10

SLC25A1

SLC25A12

SLC25A13

SLC25A15

SLC25A17

SLC25A1:

SLC25A20

SLC25A22

SLC25A24

SLC25A25

SLC25A29

SLC25A32

SLC25A36

SLC25A40

SLC25A44

SLC25A46

SLC27A1

SLC27A2

SLC27A3

SLC27A4

SLC29A

SLC29A1

SLC30A6

SLC30A7

SLC30A9

SLC33A1

SLC35A1

SLC35B2

$\mathrm{SLC} 35 \mathrm{C} 2$

SLC35E1

SLC35F6

SLC37A1

SLC37A4

SLC38A1

SLC38A2

SLC38A1C

SLC39AE

SLC39A

SLC39A1

SLC39A11

SLC39A1

SLC41A:

SLC44A1

SLC44A:

\begin{tabular}{|l|l|}
\hline SILAC & mRNA \\
\hline
\end{tabular}

SLC2A1 $\quad$ SLC2A1

SLC3A2

-

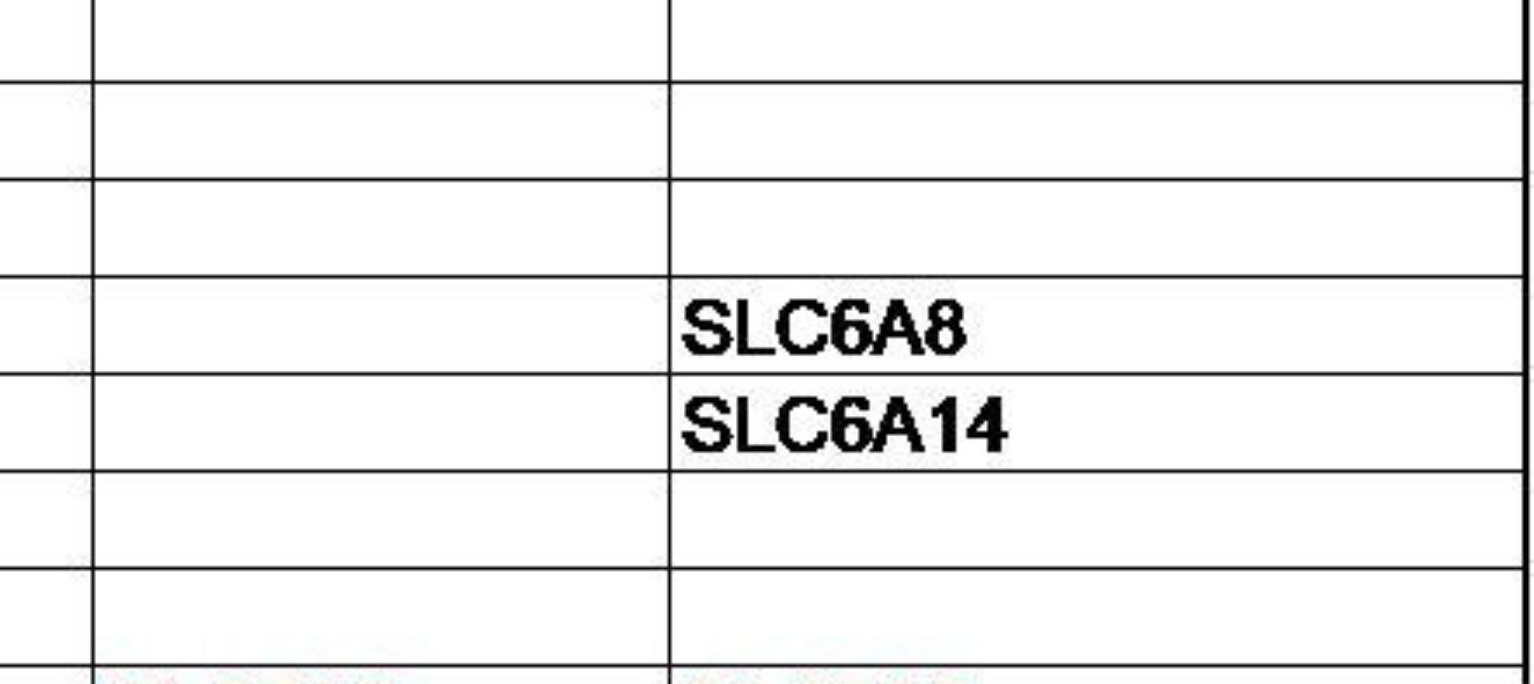

\begin{tabular}{|l|l}
\hline SLC7A5 & SLC7A5 \\
& \\
\hline & SLC7A60S \\
\hline & SLC7A11
\end{tabular}

\begin{tabular}{|l|l}
\hline & \\
\hline SLC9A3R1 & \\
& \\
& SLC9A7
\end{tabular}

\begin{tabular}{|l|l}
\hline & SLC9A7 \\
\hline & \\
\hline & SLC12A2
\end{tabular}

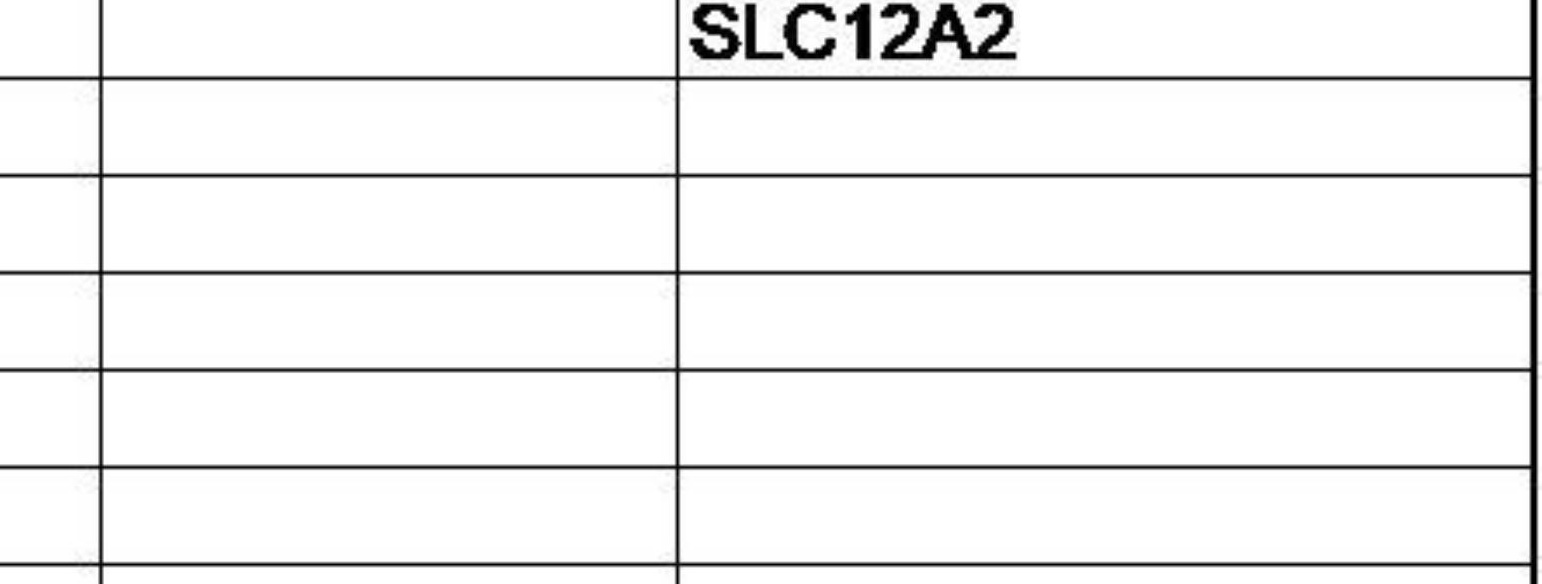

\begin{tabular}{|l|l|}
\hline & \\
\hline SLC25A3 & \\
\hline SLC25A4 & \\
\hline & \\
\hline SLC25A6 & \\
\hline SLC25A10 & \\
\hline SLC25A11 & \\
\hline & \\
\hline
\end{tabular}

SLC25A13

\begin{tabular}{|l|l|} 
& \\
\hline & SLC25A19 \\
\hline & \\
\hline &
\end{tabular}

L25A23

\begin{tabular}{|l|l|}
\hline & SLC25A23 \\
\hline & \\
\hline & SLC25A30 \\
\hline & SLC25A33 \\
\hline & SLC25A36 \\
\hline & SLC25A44 \\
\hline & SLC26A2 \\
\hline & \\
\hline & SLC27A2 \\
\hline & SLC27A3 \\
\hline
\end{tabular}

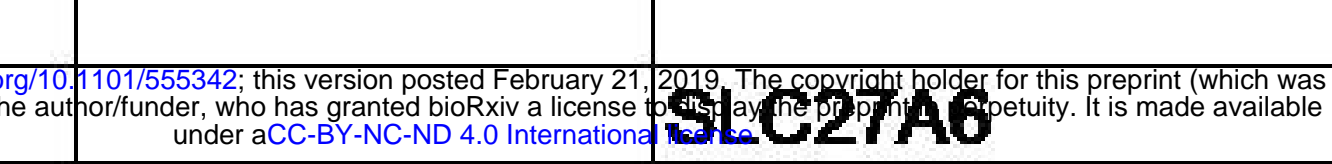

\begin{tabular}{|l|l|}
\hline & SLC30A5 \\
\hline & \\
\hline & SLC30A7 \\
\hline & \\
\hline & \\
\hline
\end{tabular}

MIR4647 // SLC35B2

\begin{tabular}{|l|l}
\hline & \\
\hline & CENPA I/ SLC35F6 \\
\hline & SLC37A1
\end{tabular}

\begin{tabular}{|l|l|}
\hline & CENPA // SLC35F6 \\
\hline & SLC37A1 \\
\hline & SLC38A1 \\
\hline &
\end{tabular}

\begin{tabular}{|l|l|}
\hline & \\
\hline & \\
\hline & SLC39A6 \\
\hline & SLC39A8 \\
\hline & \\
\hline & \\
\hline & SLC41A2 \\
\hline & \\
\hline
\end{tabular}
SLC50A1

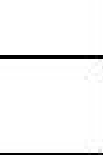

\begin{tabular}{|l|l|}
\hline & \\
\hline & \\
\hline
\end{tabular}

